\title{
Low-cost UAV surveys of hurricane damage in Dominica: automated processing with co-registration of pre-hurricane imagery for change analysis
}

\author{
Martin Schaefer ${ }^{1}$ (D) - Richard Teeuw ${ }^{2}$ (D) Simon Day $^{3}$ D . Dimitrios Zekkos ${ }^{4}$ (D) \\ Paul Weber $^{1}$ (D) Toby Meredith $^{5}$. Cees J. van Westen ${ }^{6}$ (D)
}

Received: 20 February 2019 / Accepted: 29 February 2020 / Published online: 12 March 2020

(C) The Author(s) 2020

\begin{abstract}
In 2017, hurricane Maria caused unprecedented damage and fatalities on the Caribbean island of Dominica. In order to 'build back better' and to learn from the processes causing the damage, it is important to quickly document, evaluate and map changes, both in Dominica and in other high-risk countries. This paper presents an innovative and relatively low-cost and rapid workflow for accurately quantifying geomorphological changes in the aftermath of a natural disaster. We used unmanned aerial vehicle (UAV) surveys to collect aerial imagery from 44 hurricane-affected key sites on Dominica. We processed the imagery using structure from motion (SfM) as well as a purpose-built Python script for automated processing, enabling rapid data turnaround. We also compared the data to an earlier UAV survey undertaken shortly before hurricane Maria and established ways to coregister the imagery, in order to provide accurate change detection data sets. Consequently, our approach has had to differ considerably from the previous studies that have assessed the accuracy of UAV-derived data in relatively undisturbed settings. This study therefore provides an original contribution to UAV-based research, outlining a robust aerial methodology that is potentially of great value to post-disaster damage surveys and geomorphological change analysis. Our findings can be used (1) to utilise UAV in post-disaster change assessments; (2) to establish ground control points that enable before-and-after change analysis; and (3) to provide baseline data reference points in areas that might undergo future change. We recommend that countries which are at high risk from natural disasters develop capacity for low-cost UAV surveys, building teams that can create pre-disaster baseline surveys, respond within a few hours of a local disaster event and provide aerial photography of use for the damage assessments carried out by local and incoming disaster response teams.
\end{abstract}

Keywords Hurricane $\cdot$ UAV $\cdot$ Structure from motion (SfM) · Image co-registration · Disaster response $\cdot$ Damage assessment $\cdot$ Change analysis

Martin Schaefer

martin.schaefer@port.ac.uk

Extended author information available on the last page of the article 


\section{Introduction}

On 18 September 2017, category 5 hurricane Maria made landfall on Dominica, a small island state in the Caribbean/Lesser Antilles (Fig. 1), the first of that intensity to hit Dominica in the past 30 years, causing widespread damage and loss of life (Government of Dominica 2017; Pasch et al. 2018). The impact on the island was unprecedented, especially in environmental terms, with massive loss of trees on the heavily wooded slopes. The wind and heavy rainfall, combined with the high vegetation load coming from the slopes and the transportation of soil and boulders by water, caused numerous multi-hazard situations (Fig. 2) (Pasch et al. 2018). Around 10,000 landslides occurred (Fig. 2a) due to the extreme rainfall and physical uprooting of trees. The landslides fed debris flows (Fig. 2b) into the river systems, affecting an area of $14 \mathrm{~km}^{2}$ and causing catastrophic damage where they interacted with infrastructure and housing (Fig. 2c, d). The hurricane caused 64 deaths, affected 71,393 people and caused a total damage of 1.456 billion US\$ (Université catholique de Louvain 2019).

The drastic changes to the landscapes of Dominica, both the geo-ecological changes in the rural landscape and the damage, destruction and burial by sediment in inhabited areas, highlight the need for rapid mapping and quantification of such changes. This can lead to a better understanding of what happened during hurricane Maria and thus provide the knowledge base to guide the reconstruction of Dominica, as well as development of activities in other countries that are at high risk from similar extreme storm events. In this paper, we present the results of a damage survey undertaken after Maria that used unmanned aerial vehicles (UAVs), alternatively known as drones or remotely piloted aircraft systems (RPAS). In addition to capturing primary post-hurricane data,

\section{Hurricane Maria 17-19th September 2017} [HURDAT2 (NOAA)]

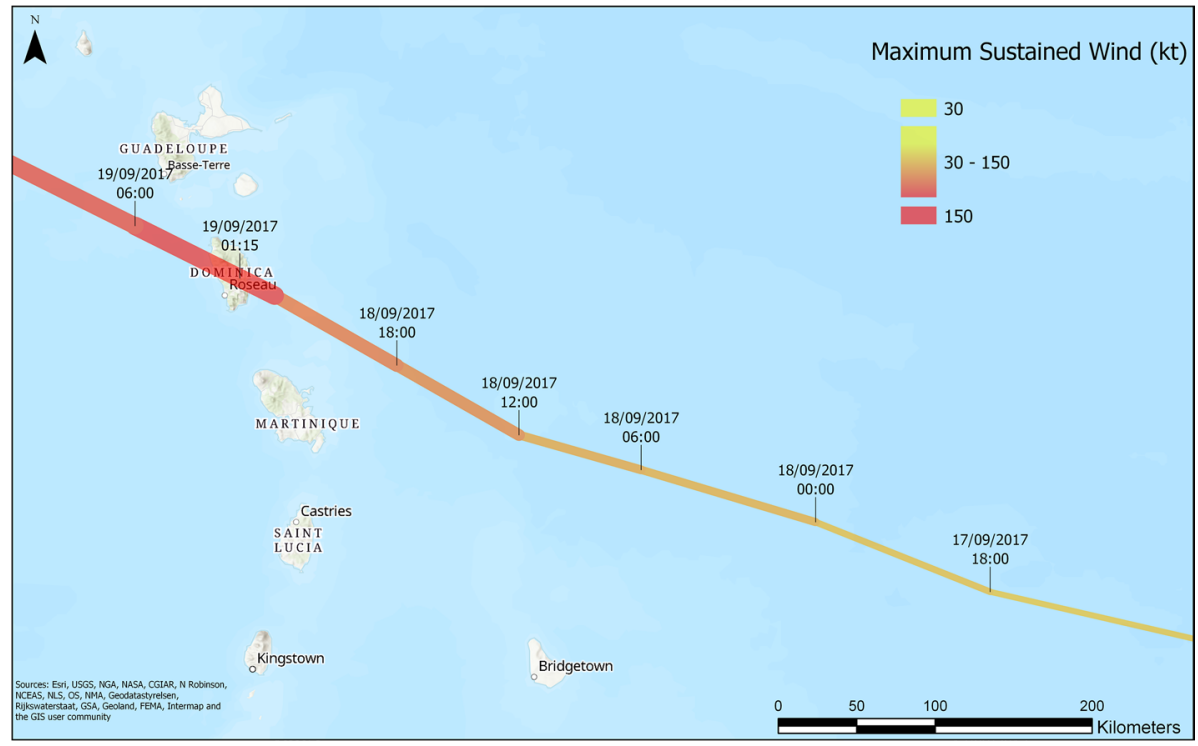

Fig. 1 Hurricane Maria track and intensity in relation to Dominica (Arcgis Pro 2.3) 


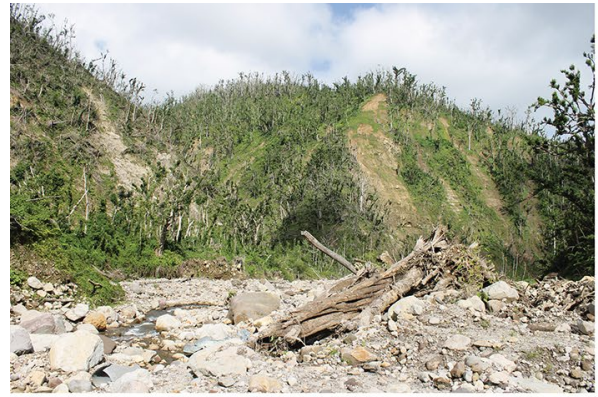

(a)

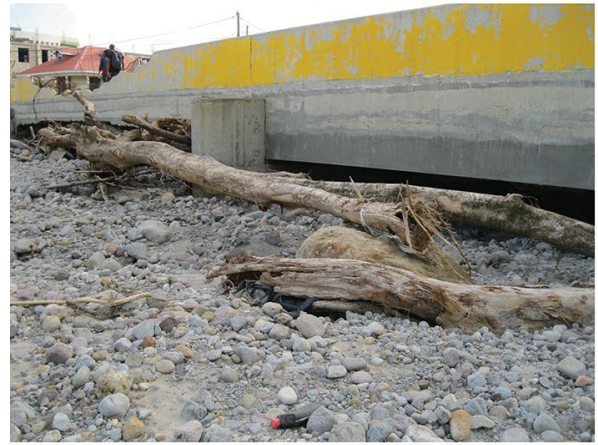

(c)

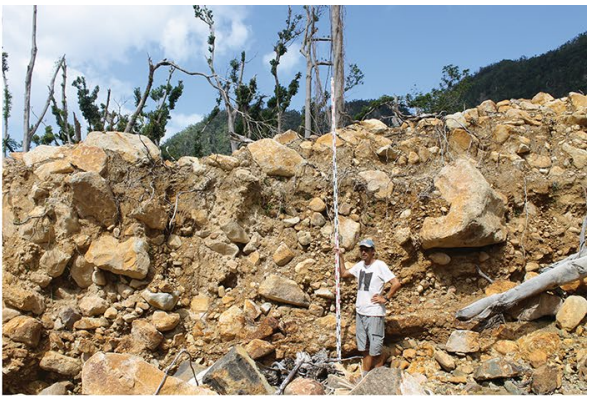

(b)

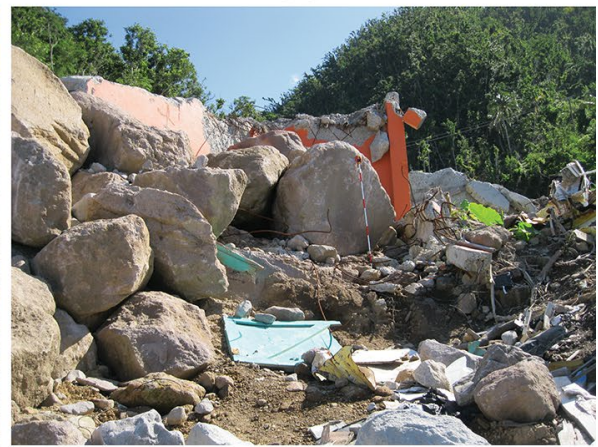

(d)

Fig. 2 Field pictures from January 2018 survey showing selected geomorphological processes (Adobe Illustrator): a Landslide scars, now partly vegetated, on a mountainside above the Pichelin River. The landslide scars expose weathered bedrock of lava flows and pyroclastic deposits (Day, S.). b Large boulders and tree debris in landslide runout deposit, with some debris flow characteristics, near Sulphur Springs resort, Soufriere. Levelling staff extended to full $5 \mathrm{~m}$ length (Day, S.). c Tree debris forming a plug under northern span of bridge on Roseau River in central Roseau, largely buried by the poorly sorted alluvium that accumulated upstream of the plug (Heidarzadeh, M.). d Buildings destroyed by boulder-rich debris flow in steep channel, Champagne (Heidarzadeh, M.)

we were able to work with pre-Maria UAV data captured by Zekkos et al. (2018b) in August-September 2017, i.e. three weeks before the hurricane landfall. This enabled a before and after comparison, with change analysis in areas of erosion and deposition being useful for the disaster forensic investigations.

UAVs are inexpensive platforms for rich data capture, as they can produce both metric three-dimensional models and orthophotographs, or 'photo-maps', of areas of interest. They have become a major tool for environmental and/or geomorphological surveys, as well as for emergency response (e.g. assessment and monitoring of major fires), postdisaster damage assessments and monitoring aspects of humanitarian crises, such as the growth of refugee camps (Turner et al. 2012, 2016; Javernick et al. 2014; Clapuyt et al. 2016). There are two main types of UAV, rotary or fixed-wing (Greenwood et al. 2019). Fixed-wing UAVs provide a wider coverage on an equivalent battery, whereas rotary UAVs are better suited for low-level flying and hovering, especially in constrained areas such as Dominica's mountainous terrain and steep-sided valleys.

Alternative sources of remotely sensed information either lack the centimetre resolution (e.g. the 0.3 to $30 \mathrm{~m}$ pixels of most Earth Observation (EO) satellite imagery), the temporal 
resolution (e.g. aerial photography, and optical satellite imagery in humid climatic regions is often obscured by cloud coverage) or are expensive to acquire and process (e.g. commercial sub-metre pixel satellite imagery and vertical aerial photography from aeroplanes). Other ground survey methods are available, but lack the rich data (e.g. total station surveys or surveys using global navigation satellite system point data), or are costly in terms of equipment (e.g. airborne laser scanning, terrestrial laser scanning). They can also be hampered by access and safety aspects, which are particularly problematic in the context of post-disaster surveys.

In contrast to the limitations of other remote sensing platforms, UAVs can be deployed quickly and repeatedly, are relatively inexpensive and can safely access otherwise inaccessible areas, all at centimetre-scale spatial resolutions. However, there are limitations with UAV, notably battery-dependent flying time. There are also height limitations and limits on beyond visual line of sight flying (BVLOS) imposed by the technology and aviation laws, which together mean that the coverage they can provide is restricted to small areas (i.e. areas of $\mathrm{m}^{2}$ dimensions to a few hectares). Another limitation is the weather, with flight requiring dry conditions and winds of $<10 \mathrm{~m} / \mathrm{s}$, depending on the UAV platform. There are also legal limitations based on safety and privacy considerations (OCHA 2014). UAV operations need to be planned well and operated by experienced pilots, and local aviation regulators should always be consulted before planning on operating a UAV. Good guidance on the use of UAV in disaster relief and post-disaster mapping is provided by the Humanitarian UAV Network (2018) as well as the United Nations Office for the Coordination of Humanitarian Affairs (OCHA 2014).

UAV data collection works best in conjunction with differential Global Navigation Satellite System (DGNSS), either through ground control points (GCP) or direct georeferencing using correction solutions (Barry and Coakley 2013; Javernick et al. 2014; Turner et al. 2014; Caroti et al. 2015). When that is not possible, due to logistical or safety aspects of deploying GCPs or lack of a correction signal, alternative methods can be employed, such as direct georeferencing using uncorrected GNSS. All UAV are equipped with an internal GNSS, and an inertial measurement system (IMU) and images are geotagged. The accuracy of these directly georeferenced images is dependent on the sensor. Most commercial UAVs provide only uncorrected accuracy for their internal GNSS (ca. $5 \mathrm{~m}$ ), in line with other consumer grade GNSSs (Schaefer and Woodyer 2015). Advanced UAV employ realtime kinematic correction solutions (RTK) that provide accuracies on a par with GCP controlled data (Turner et al. 2014). A similar solution is post-processing kinematic (PPK), where the GPS data are not transmitted to the UAV in real time, but positions are postprocessed, resulting in the same accuracy as RTK. References here to RTK systems shall be taken to include PPK. These solutions are costly, however, and negate some of the cost benefits of UAV systems. A third method is to derive GCP from existing high accuracy data, if available. Taking into account the limitations above, UAV can produce rich data for geomorphological analysis and infrastructure inspection over small areas. UAV data can be used in combination with lower-resolution data with larger coverage, such as manned aerial photography and satellite imagery, as well as providing a ground truth validation data set for the other data.

The aims of this paper are thus to: (1) outline relatively low-cost UAV survey methods for post-disaster damage assessment; (2) determine the accuracy of matching UAV data covering areas that have undergone substantial change; and (3) guide future applications of UAV in post-disaster geomorphological change assessments. Most papers concerned with the accuracy of UAV-derived data work with highly controlled reference data for comparison with the gathered data (Barry and Coakley 2013; Caroti et al. 2015; Clapuyt et al. 
2016). This paper is different in that the study area either has no reference data or, due to storm damage, the reference data are significantly altered, which is closer to reality in postdisaster settings. The paper will also make recommendations to local partners for providing reference points in areas that are predicted to undergo future change. The study furthermore provides a method for automated processing of a large number of data sets in the processing software, via Python programming, significantly cutting data processing time.

\section{Methods}

The methods employed by this study were to acquire data by UAV, using a purpose-built Python script to automate structure from motion (SfM) processing in order to generate DSMs and orthophotographs, and matching of UAV data collected with varying methods to enable comparison and change detection. For the matching of the UAV data, we use UAV imagery acquired by Zekkos et al. (2018b) a few weeks before hurricane Maria. Our focus is on areas where data overlap between the pre- and post-hurricane surveys allows quantitative comparison, and, thereby, quantitative mapping of change between the two surveys. This can be used, upon interpretation, to quantify the impact of the hurricane.

\subsection{Data capture and processing}

The 2017 data were collected by Zekkos et al. (2018b) between 22 August and 3 September 2017, approximately three weeks before hurricane Maria made landfall. Data collection took place at nine locations, the majority of which were floodplains. At each location, lawn-mower type flight paths were planned with still imagery collected in order to create 3D models of the target areas. In addition, an upstream flight with video acquisition was conducted in an effort to identify any debris blocking the main riverbed.

Imagery was captured using a DJI Phantom 4 Pro (Table 1). The team also employed a Trimble R10 GNSS, together with survey staff from the Government of the Commonwealth of Dominica (GoCD) and surveyed between 13 and 40 GCP per area prior to image capture. The data were post-processed against Trimble CenterPoint ${ }^{\mathrm{TM}} \mathrm{RTX}^{\mathrm{TM}}$ post-processing service. The number of GCP was controlled by the size of each area. Flying height was dictated by the surrounding area and varied between survey sites and chosen to deliver centimetre-level ground sampling distance (GSD). Imagery was collected with $80 \%$ front and $60 \%$ side overlap.

Table 1 Key technical specifications of the drones used in the 2017 and 2018 surveys

\begin{tabular}{llll}
\hline Specification & Phantom 3 & Phantom 4 & Phantom 4 Pro \\
\hline Weight (g) & 1216 & 1380 & 1388 \\
Diagonal size (mm) & 350 & 350 & 350 \\
Sensor size (megapixels) & $1 / 2.3^{\prime \prime}(12 \mathrm{M})$ & $1 / 2.3^{\prime \prime}(12.4 \mathrm{M})$ & $1^{\prime \prime}(20 \mathrm{M})$ \\
35 mm equiv. focal length $(\mathrm{mm})$ & 20 & 20 & 35 \\
GSD at 50 m (m) & 0.0214 & 0.0219 & 0.0137 \\
$\begin{array}{l}\text { Ground coverage of a single photograph } \\
\text { at 50 m (m) }\end{array}$ & $86 \times 64$ & $87 \times 65$ & $75 \times 50$ \\
\hline
\end{tabular}


The imagery was processed using Pix4D, a SfM processing package. The data output consisted of 3D point clouds, DSMs and orthophotographs. Some of the GCPs were used as checkpoints, and the error assessment of all areas shows a centimetre-level root mean square error (RMSE). More details on the data acquisition and model creation are provided in Zekkos et al. (2018b). Here, we use the 2017 data set as a baseline for assessing the accuracy of the post-Maria data as well as for change detection.

\subsection{Data capture}

The field surveys in Dominica took place four months after hurricane Maria in January/ February 2018, which was the earliest possible period for surveys following the disaster relief phase. Given this delay, there was a concern that ongoing debris clean-up activities and the reconstruction of infrastructure would limit the veracity of the geomorphological mapping and infrastructure damage assessments. Although most roads and urban areas had been cleared of hurricane debris by January 2018, significant amounts of in situ overbank sediment remained in some of the smaller villages and in places where the damage was so severe that any remaining buildings had been abandoned. In rural areas, especially in the river beds, the only clearance efforts had been concentrated on usable roads and so most of the hurricane-generated geomorphological features were still visible, as was the extent of the damage to most of the major infrastructure.

Surveys were performed using a DJI Phantom 3 (P3) and a DJI Phantom 4 (P4) UAV (Table 1), both of which have a smaller image sensor than the UAV used by Zekkos et al. (2018b), which leads to a difference in image quality between surveys. The results below, however, show that the consumer end of the drone market provides sufficient image quality to compare surveys. The UAV kit consisted of the UAV, 4 batteries per drone, charging equipment, safety equipment and spare parts. Through the local partners, all necessary permissions were obtained from the Dominican Government via the Land Survey Department and local Air Traffic Control (ATC), and local communities were consulted before flying. The flight crew consisted of two pilots plus observers that split into two working parties. No GCPs were laid out, due to safety considerations in accessing survey areas on foot to deploy GCP in active landslide areas. The pilots aimed at a flying height above ground level (AGL) of $50 \mathrm{~m}$ (Table 1). UAV operations were performed based on the existing University of Portsmouth Operations Manual for UAV.

Overall, the UAV surveying was deemed successful, and many more sites were surveyed than expected. Pre-survey planning had allowed for a number of days to be lost due to poor weather or other delays, which is an important consideration in planning UAV surveys. Over the course of the actual aerial survey, only one day was lost due to poor weather and another half-day was lost due to minor damage sustained by one UAV during flying operations. A total of 115 flights were operated over 9 days, 58 with the P3 and 57 with the P4. These flights created data in 44 distinct survey areas of varying areal sizes (Fig. 3).

\subsection{Data processing}

Processing was performed on a Windows 764 bit PC with 64 GB RAM, an Intel i7 $5820 \mathrm{~K}$ CPU and a Nvidia GeForce GTX 980 GPU. The images captured by the DJI sensors showed a high variation in exposure. As a first step, the images were processed in Adobe Photoshop Lightroom Classic CC. Only adjustments controlling exposure were applied to 


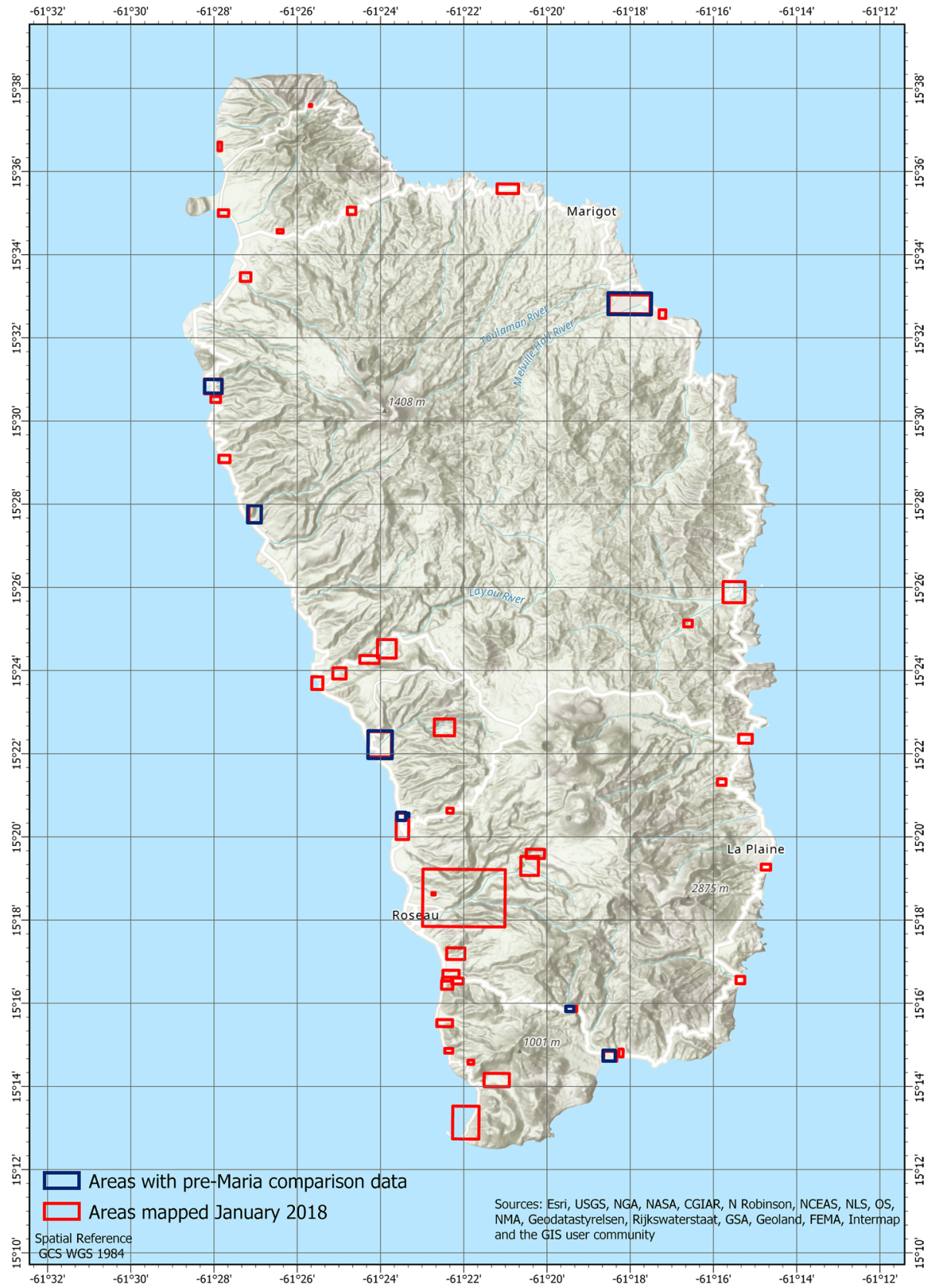

Fig. 3 Overview map of Dominica showing the extents of all areas mapped (Arcgis Pro 2.3) 
balance the pictures within an area. No adjustments were made that affect the geometry of the images, as this would have an effect on the subsequent processing.

\subsection{SfM processing}

The SfM processing was performed with AgiSoft PhotoScan 1.4 (PS). PS is a dedicated photogrammetry package for the creation of 3D data from overlapping images released in 2010 (AgiSoft 2017; De Reu et al. 2013). The images were processed in PS by first aligning the images and then computing a dense point cloud from photogrammetric measurements of the overlapping images. This dense point cloud is used to compute a DEM and, in combination with the derived DEM, an orthophotograph. This process is described in detail in the literature (Westoby et al. 2012; De Reu et al. 2013; Clapuyt et al. 2016; Zekkos et al. 2018a). Preliminary processing was done to provide the team on the ground with usable data with only default settings applied. After the initial rush, a more considered approach was taken. Within SfM processing in PS, there are a number of controls one can apply to the processing. The impact of each control depends on the data, and there is a lack of the literature on how to decide which controls to apply for different scenarios. The main controls are:

- Adaptive camera fitting: In traditional photogrammetry, a calibrated photogrammetric camera is used with accurately measured camera characteristics, such as focal length, principal point position and distortion, all of which have an influence on the modelling process. These are derived from the data as part of the SfM process. PS calculates how reliable these parameters are as part of the adaptive camera fitting and automatically uses the best combination. This process prevents divergence of parameters in aerial photography (De Reu et al. 2013; Mallison 2015; Marius et al. 2017; Agisoft 2018). Adaptive camera fitting was set to on.

- Depth filtering: During dense cloud generation, PS produces depth maps and offers a selection of algorithms to filter out errors. The filters range from mild to aggressive or can be set to none, and as the filters progress, more small details are filtered out. Aggressive is normally recommended for aerial projects; however, mild is suggested for areas with poorly textured roofs (Agisoft 2018). Mild was chosen for this project, to retain more details in the complex Dominica landscape.

- Tie point limit: Tie points are used between pictures to match identical points. PS uses an automated matching process to find these points. By setting the limit to zero, no filtering is applied (Agisoft 2018). Set to zero for this project.

- Key point limit: The key point limit is used to control how detailed PS will sample an image. Setting a higher number increases the computational requirements of the process, and posts in relevant photogrammetry forums suggest that the cost-benefit curve levels off at around 40,000 key points (Marcel 2015; Mallison 2015; Agisoft 2018). A value of 40,000 was used in the project.

- Gradual selection (GS): After tie point creation, each tie point is assigned quality data that expresses the confidence in the tie point. PS allows for a gradual selection of these points in order to remove low-quality points. No clear guidance is available for the process, and there are differing accounts on various forums as to which values to choose (Harwin et al. 2015; Mallison 2015; Mertes et al. 2017; Agisoft 2018). The process used in this project is outlined below. 


\subsubsection{Automated Python script}

SfM is a computationally intensive process, where each step can take from several minutes to hours depending on the number of images and processing settings. In order to streamline the processing of 44 areas, an automated approach was taken. PS allows for batch processing and has a Python interface for scripting. The Python approach was taken for this project as it allowed for more control over the process. A complete automation script was written that can process and export all areas in one go, without user intervention. This means the PC can be left to run continuously for several days, without needing user input. The script is published on GitHub (Schaefer 2018); the version used in this project was 6.2. Figure 4 outlines the process flow chart. To date no automated batch process has been published that incorporates an automatic GS process. GS is an important process to improve the image matching algorithms (Harwin et al. 2015; Mallison 2015; Mertes et al. 2017; Agisoft 2018), but it is also time-consuming, especially if multiple models or areas are required. To manually process the workflow required to produce the best models following each image alignment would take up several more hours of manual intervention, and the process would have to wait until an operator was available following the alignment. Scripting this step is an addition to the PS workflow that allows a fully automated process without any user intervention, and an optimal use of time when a short turnaround can be highly beneficial. The script also allows for nonspecialist users to produce high-quality models quickly with minimal training.

In PS, each area is organised in a chunk. Chunks are processed separately and in sequence, allowing to process either many data sets or a data set that is too large to process as one model. The initial steps are to load the images of each area into a chunk and give the chunk a relevant name. PS reads the direct georeference of each image from the image's metadata, stored in the EXIF, or can be loaded separately from a log file, depending on UAV system. The coordinate reference system (CRS) of each chunk needs to be checked; in the case of GPS data, this is WGS84. The script sets the output directory and a file prefix from user input. The latter is used to allow differentiation of multiple runs of processing with different settings. The script creates custom menu items in PS and has an option to run the complete process for all chunks.

The script first calculates an estimate of the image quality of each photograph taken and discards images below a threshold; the default is set to 0.5 . This value should be considered for each data set, where images from a larger sensor can be expected to exceed 0.8 , but the small sensor of a P3 or P4 is set to 0.5 . The script then aligns all images in each chunk and optimises the model before applying the gradual selection process. The gradual selection strategy selected is based on a number of sources and adapted to produce consistent results (USGS 2017; Mallison 2015; Marius et al. 2017). The aim of the script is to reduce the tie points to $80 \%$ of the original tie points in three steps, retaining only the highest quality points. The percentage is adaptable in the script if needed.

In the first step, the reconstruction uncertainty (RC) is addressed. High RC values are a measure of points that deviate noticeably from the object surface (Agisoft 2018). RC is set to a threshold of 10 initially, but automatically adapted should the number of tie points selected exceed $50 \%$ of the total. The model is then optimised. The second step processes projection accuracy (PA). PA is a measure of the projections of each tie point onto the surface (Agisoft 2018). The initial PA threshold is set to 2 and auto-adjusts to select up to $50 \%$ of the tie points left after step 1 . The model is then optimised. 


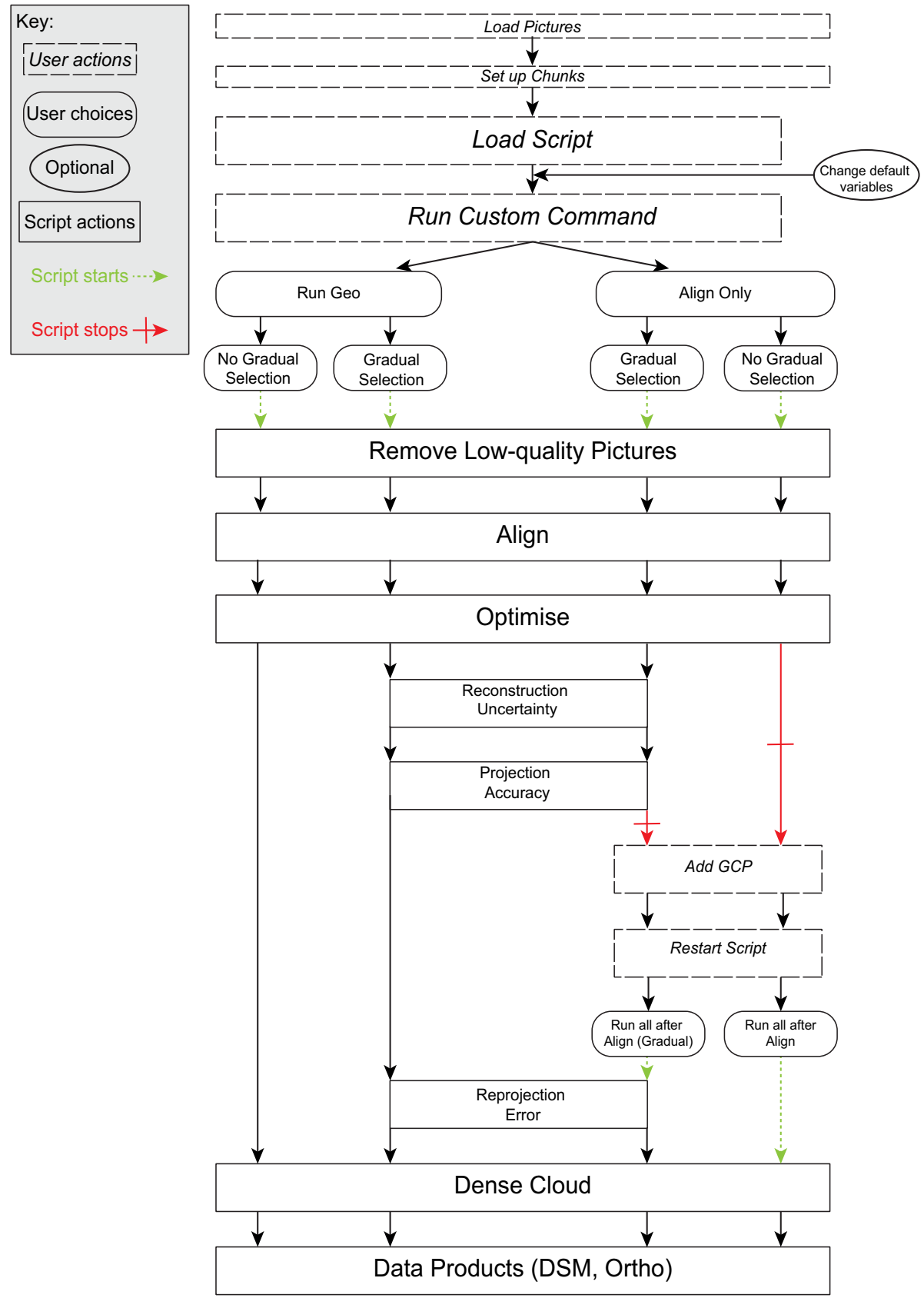

Fig. 4 Python script process flow chart (Adobe Illustrator)

The final step is to filter points based on reprojection error (RE). If GCPs are to be introduced to the model, the script offers the facility to break before this stage; the reprojection error should be processed after the GCPs have been assigned. A high RE is a measure of 
poor localisation of a tie point (Agisoft 2018). The script runs the RE filter multiple times, each round selecting $10 \%$ of remaining tie points and optimising the model until the $80 \%$ total reduction has been achieved.

The script then creates dense clouds at high accuracy, orthophotographs and DSM for each chunk, which are then exported to the output folder. The export CRS was set to WGS 84/UTM zone $20 \mathrm{~N}$ (EPSG::32,620) to match the existing data. A log file is also created in the data output folder that records all settings used. The script allows for a semi-manual approach where it enables GCP addition after processing PA, as some sources (USGS 2017) place the GCP process between the PA and RE, although the authors have subsequently not found any accuracy improvement from doing this. Adding the GCP to the project and then using the whole automated process will save time while not affecting accuracy significantly. The script further allows the user to change some of the settings from the chosen default, e.g. image quality threshold or filtering method. In this way, all 44 areas were processed in ca. $66 \mathrm{~h}$, without user interaction.

\subsection{Pre-/post-hurricane change analysis}

The data needed to be processed in three dimensions to be matched for change detection. The 2017 data were used as a baseline for comparison. There are eight areas where data overlap for pre- and post-hurricane Dominica (Fig. 3). Matching of photographs is normally done with GIS software using georeferencing, which uses XY coordinates. In this case, however, the data needed to be matched in three dimensions, something GIS packages do not support. Two methods were explored: (1) matching using CloudCompare (CC) (https://www.cloudcompare.org) and (2) matching in PS based on GCP derived from the 2017 data. The main issue in matching the two data with either method was the amount of change between the surveys due to the impact of hurricane Maria (Fig. 5a, b). The lack of unchanged points or areas of reference made co-registration very difficult.

$\mathrm{CC}$ can match data based on common points or by matching areas of overlap (CloudCompare 2015). Where possible, the overlap method was attempted. Intact roofs in the area of overlap were selected and segmented from the main cloud. An initial point-based registration was made and then a fine registration of the roof areas (Fig. 6), or in the case of Douglas Charles International Airport, the runway and taxi lanes. The resulting transformation matrix was then applied to the whole cloud. In areas where there were insufficient areas of overlap, only the initial point-based approach was taken. CC only applies a transformation matrix to the whole area, and it does not change the shape of the data.

The second method established common GCP between the data, where possible, with the 2017 data being used as a reference. Features prioritised during the process were clear features on the ground and away from areas with large changes in elevation; good examples are road markings. Where these were insufficient, apexes on roofs or edges of solar panels were used. In some areas, this worked well; Douglas Charles Airport provided ample markings on the run and taxi area, but in other areas, finding common points proved difficult, such as Pichelin village, which had a high degree of change and, compounding this, a more limited area of overlap (Fig. 7). The GCPs were placed on the 2017 orthophotograph in ArcGIS Pro and the elevation calculated using the Sample tool. These GCPs were used to re-run the SfM process. This involved identifying the 2017 derived GCP on the 2018 imagery and adding them to the PS model, between the PA and RC processes, which is an unavoidable manual process. 


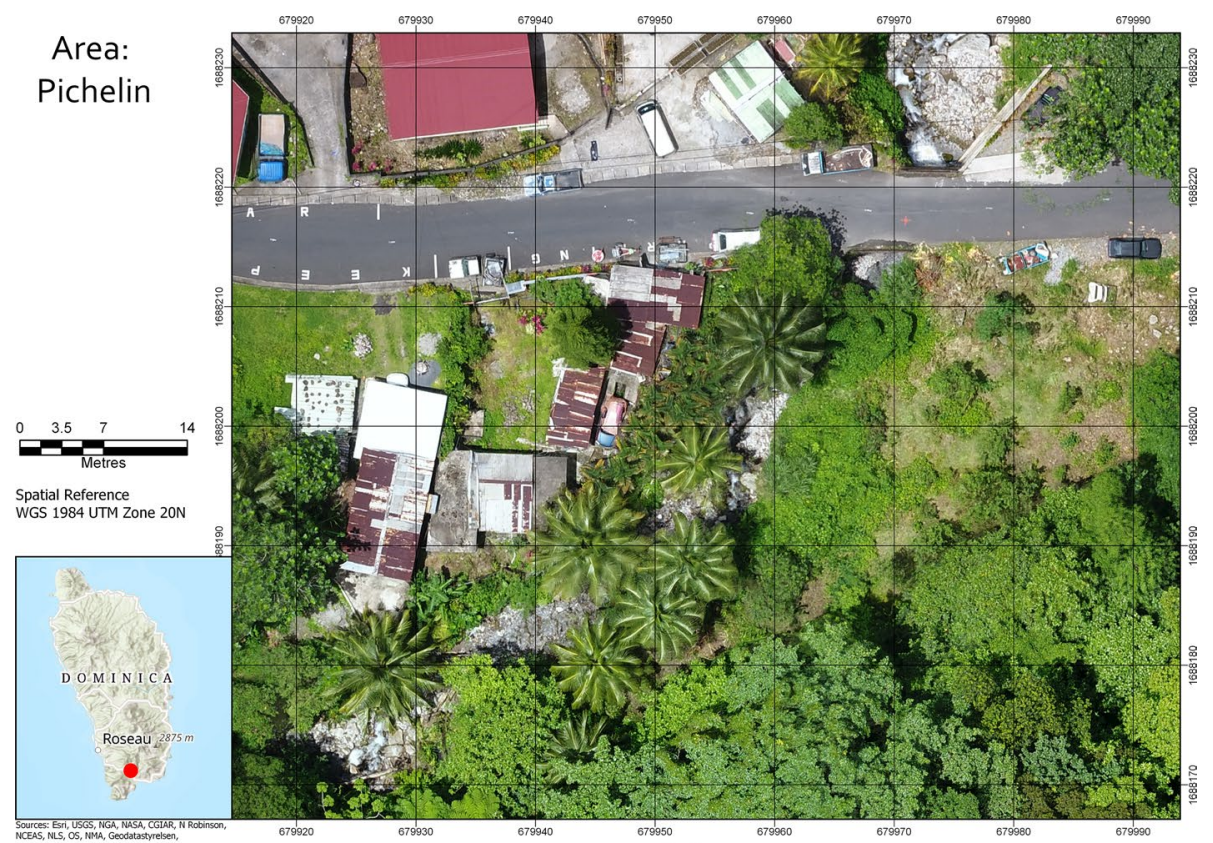

(a)

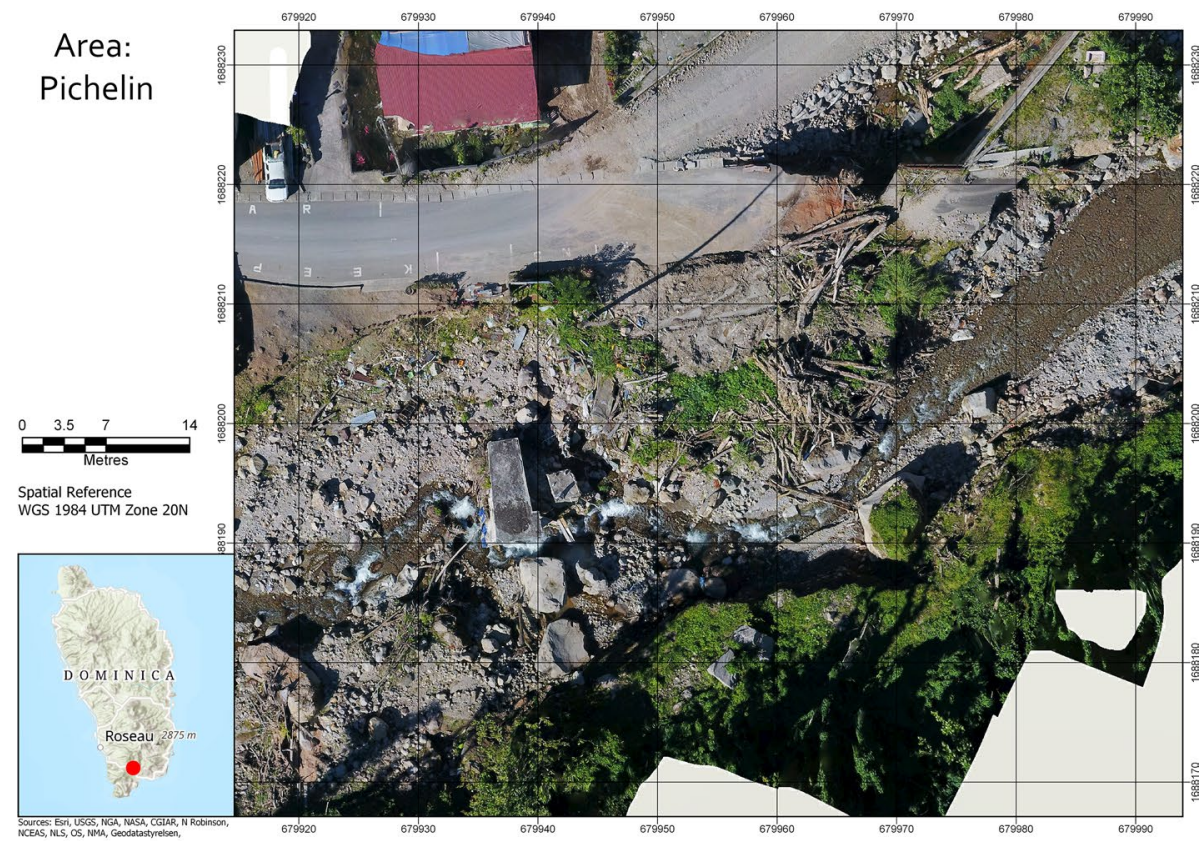

(b)

Fig. 5 Before and after comparison of an area of interest in Pichelin, Dominica. a Pre-Maria survey data of Pichelin, September 2017 (Arcgis Pro 2.3). b Post-Maria survey data of Pichelin, January 2018 (Arcgis Pro 2.3) 

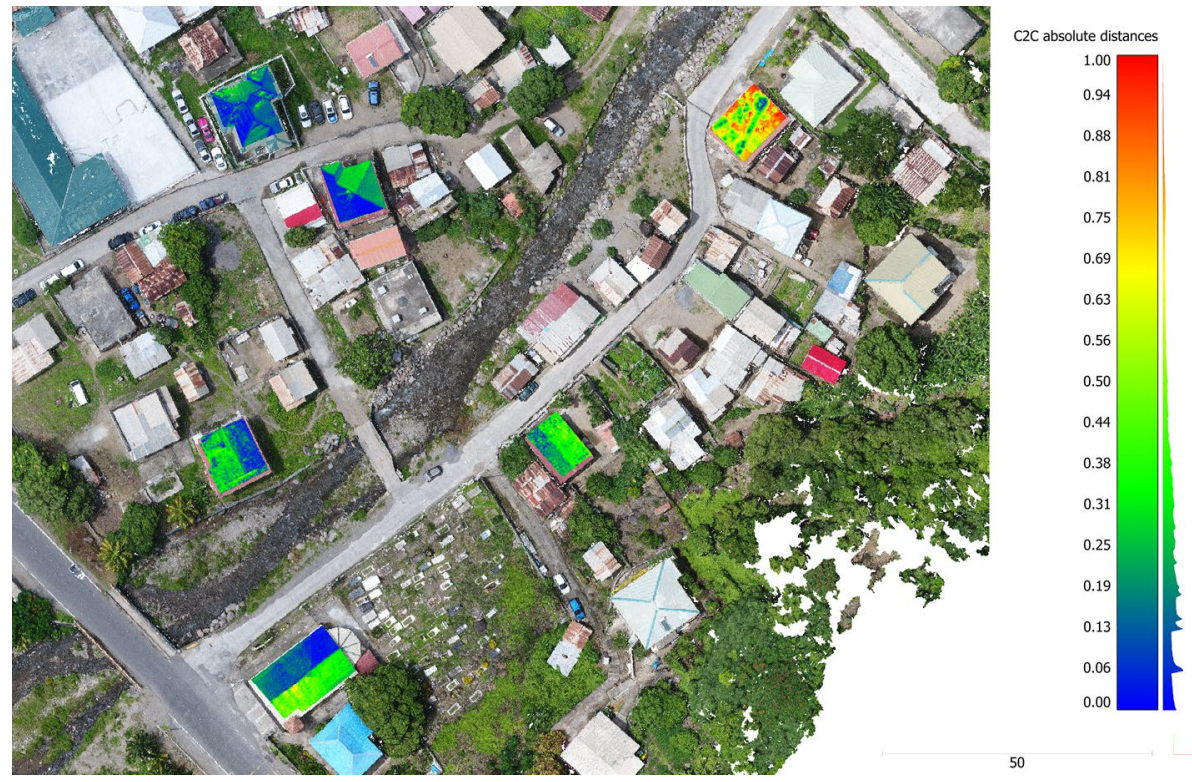

Fig. 6 Results from the alignment process using CC showing alignment error (CloudCompare, does not support TIFF output)

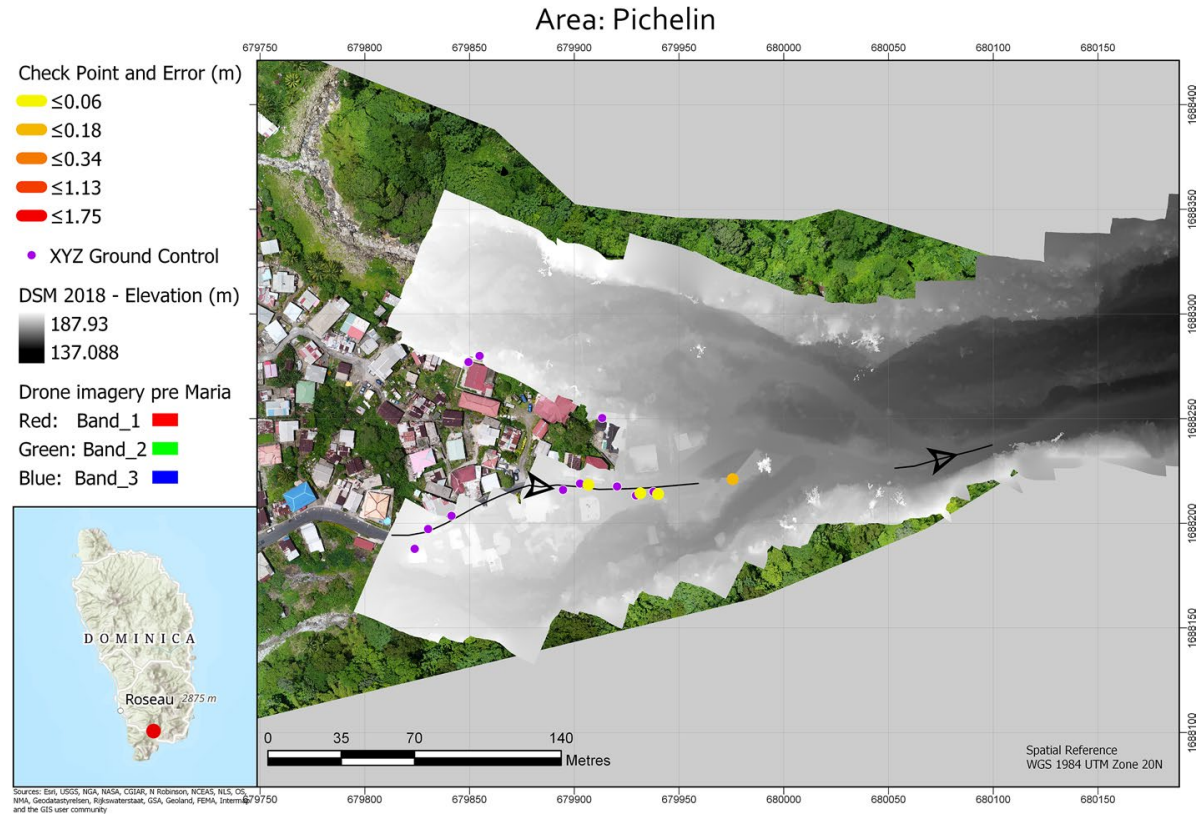

Fig. 7 Overview map of Pichelin, Dominica, showing the overlap between the 2017 and 2018 data and the GCP, profiles and check points used in error assessment. There were no usable GCP in the eastern half of the overlap. (Arcgis Pro 2.3) 


\section{Results}

The data output from the study were 44 areas processed using gradual selection without GCP. In addition, 8 areas were also processed using gradual selection with GCP derived from the 2017 data. At the current settings, PS produces orthophotographs with an average resolution of $2.5 \mathrm{~cm}$, ranging between 1.1 and $4.5 \mathrm{~cm}$, and DSM with an average resolution of $5.1 \mathrm{~cm}$, ranging between 2.3 and $9 \mathrm{~cm}$. Figure $8 \mathrm{a}-\mathrm{c}$ shows the quality of the images, DSM and point clouds produced using the Champagne Pool data as an example (Fig. 8a, b, c). The models for all areas produced results that are considered valid representations of the landscape for geomorphological assessment.

In areas where both the uncontrolled process and the GCP controlled process were available, a comparison was made between them. A significant aspect of the hurricane damage was the fact that the island was densely forested before Maria and largely de-forested after Maria. This means that the areas for geomorphological comparison were limited to areas that were not vegetated before Maria, although the data can be utilised in an ecological context to quantify changes in vegetation cover. With Douglas Charles International Airport, comparison between the GCP corrected model and the direct georeferenced model shows a tilt (Fig. 9a) as well as a significant elevation difference. The Grande Bay area shows no such tilt (Fig. 9b), with a homogenous elevation difference. Some of the higher areas of elevation difference between the two approaches in the Grande Bay data are due to model weakness in the areas that have poor image overlap (centre of Fig. 9b). The differences found are because the UAVs used in the 2018 survey were not equipped with RTKcorrected GPS and the areas where GCPs were unavailable rely solely on the internal GPS and the IMU. The IMU records UAV orientation (pitch, roll, yaw) and uses an internal barometer, which it uses for elevation in addition to the GPS altitude. It appears the altitude stored in the EXIF is based on this barometer reading, which is subject to some drift, according to technical forum posts about DJI and PS (Agisoft Forum 2018). GPS altitude accuracy is known to be 1.5 times less accurate than the plan position (XY). (Schaefer and Woodyer 2015). It is therefore expected for the absolute elevation values to be incorrect. This highlights the need for aligning the two data sets.

In order to perform change assessments, the two methods for co-registration of the postMaria data were assessed, either by using alignment in $\mathrm{CC}$ of the independently processed SfM data or by collecting GCP from the reference data and applying it to the SfM model itself.

CC can align two models and provides accurate results for laser scanned data, for instance, that has the same shape. One data issue that was apparent in SfM-derived data using non-metric cameras was systematic doming of the resulting surface (James and Robson 2014; James et al. 2017a, b). This doming was most evident in the model for the Douglas Charles International Airport at Melville Hall (Fig. 10) when compared to the reference data, as the straight and flat runway is ideal for assessing the issue. Gradual selection does to some degree mitigate against this doming effect, although it does not cancel it out. The Douglas Charles International Airport data highlighted the issue of doming in the uncontrolled SfM output and the fact that the two data sets have different shapes, which CC cannot align very well. In other areas, significant XY shifts in some sections of the model were also observed, with RMSE of between 1.3 and $2 \mathrm{~m}$.

The second method of using GCP in the SfM process gave much better results and virtually eliminated the doming effect and produced a better match of the two data, although the GCP process requires more user input and therefore increases data processing time. 


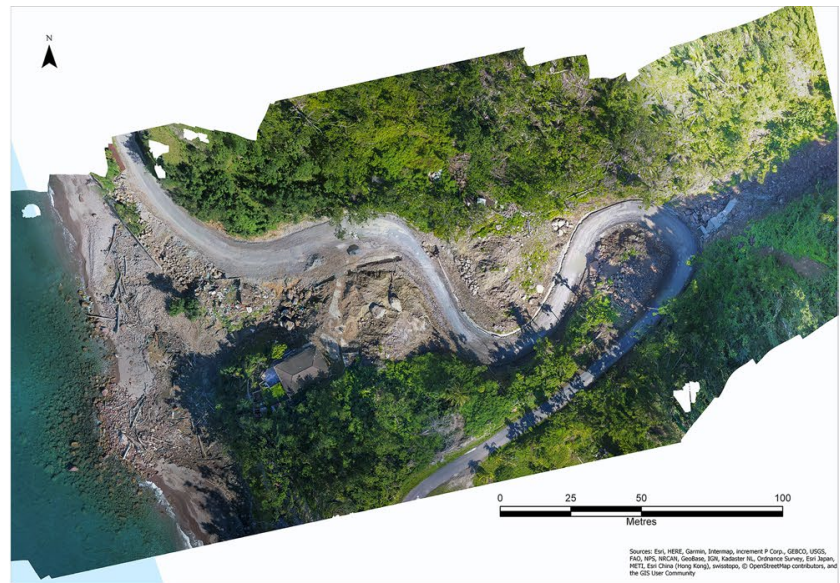

(a)

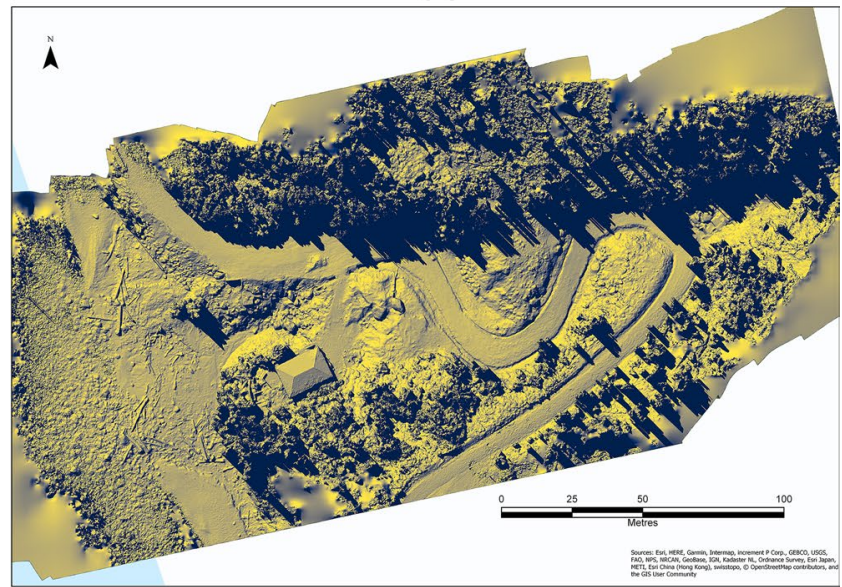

(b)

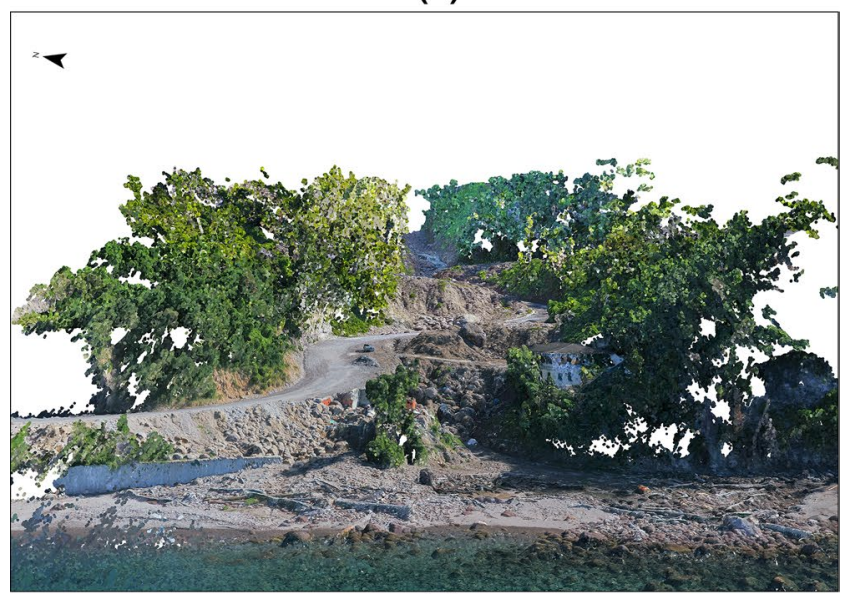

(c)

Fig. 8 Data output from Champagne Pool, Dominica, showing the three types of data produced by the SfM process. a Orthophotograph (Arcgis Pro 2.3). b Digital Surface Model (Arcgis Pro 2.3). c Point cloud (Arcgis Pro 2.3) 


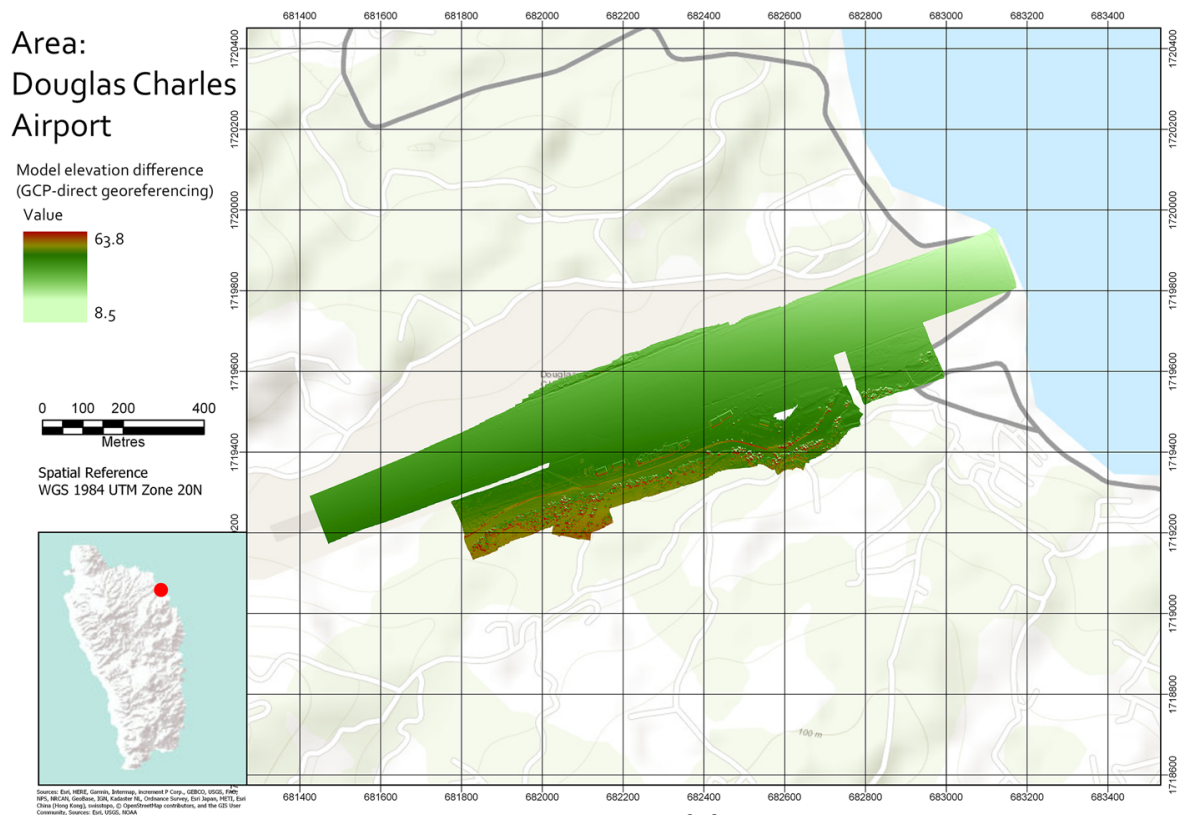

(a)

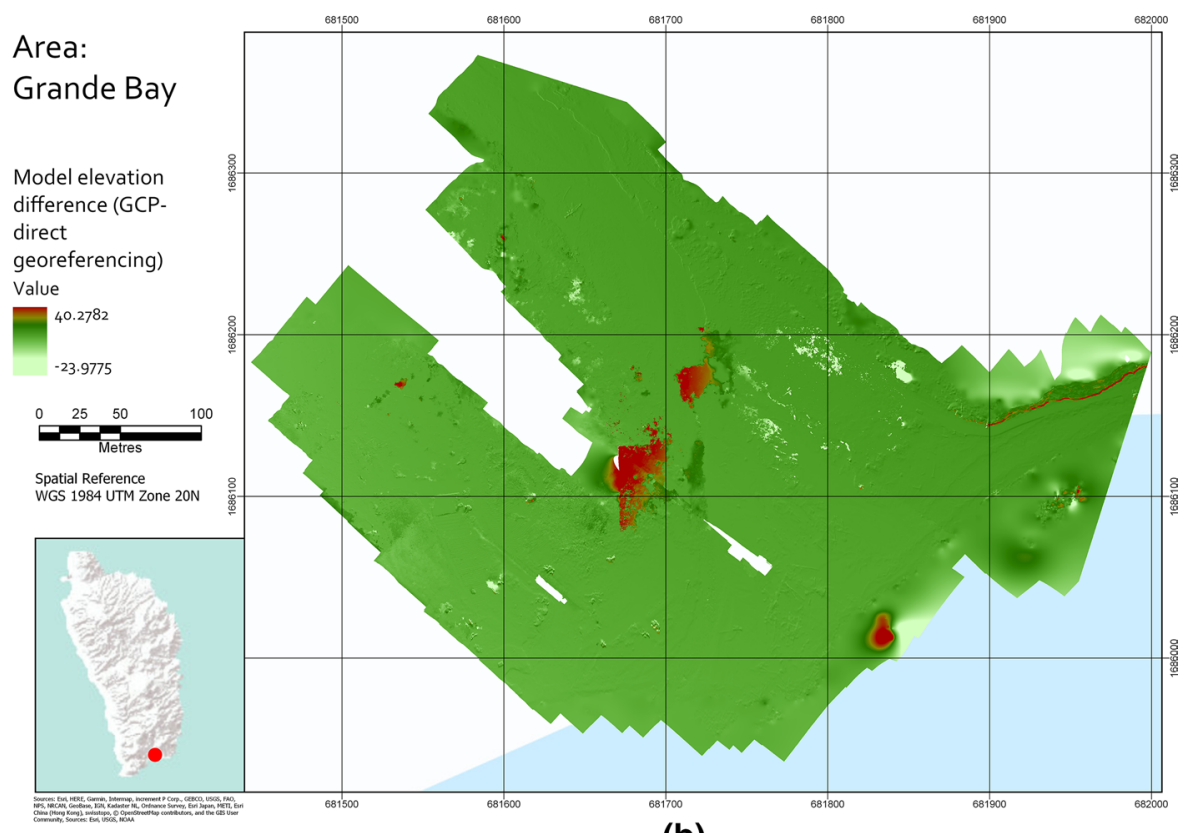

(b)

Fig. 9 Comparison between the data produced by the SfM process from direct georeferencing using the UAV internal GNSS and IMU and the data produced by the SfM process using GCP. a Map view of model elevation difference at Douglas Charles Airport, Dominica (Arcgis Pro 2.3). b Map view of model elevation difference at Grand Bay, Dominica (Arcgis Pro 2.3) 


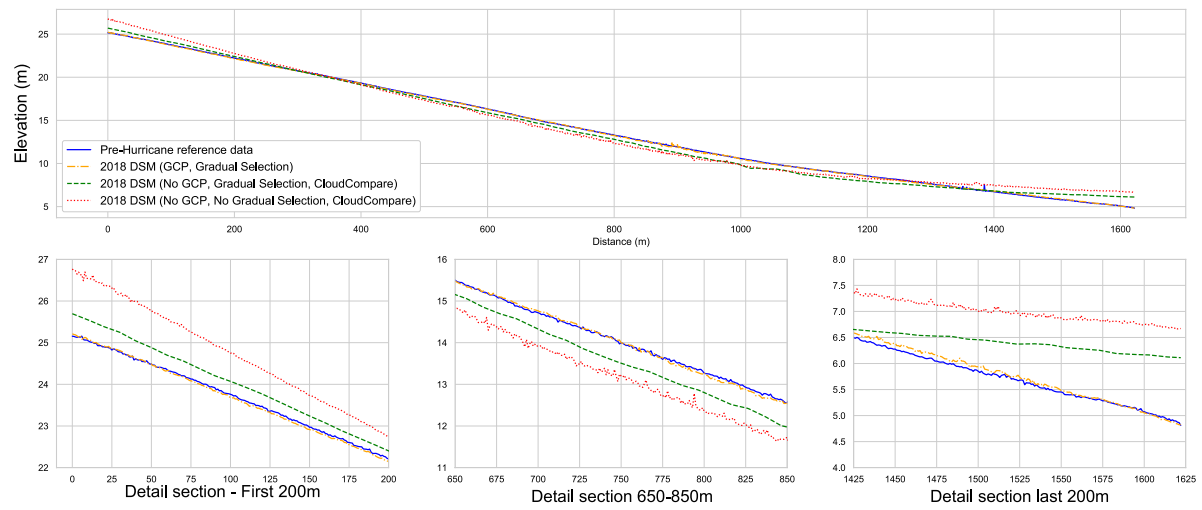

Fig. 10 Profile plots of the runway at Douglas Charles Airport comparing the 2017 reference data to the data corrected in CC, with and without gradual selection, and the data corrected using GCP (Jupyter/Matplotlib)

Figure 11 shows the XY error assessment for all areas using the GCP method. For this assessment, further common checkpoints were identified and the distances evaluated. To assess the Z-error, profiles were created in ArcGIS using the Stack Profile tool for each DSM along runways or roads and compared in a Python script. The 2017 profile was interpolated using a cubic spline, and the difference to the 2018 profile was calculated. The data showed some areas of significant difference, where trees overhanging the road in early 2017 were no longer present in early 2018 (Fig. 12a, b). Any data outside the interquartile range were removed to account for these outliers. Figure 13 shows the resulting $\mathrm{Z}$ errors. With the exception of one area (Belfast estate, North to South profile), all areas show a low error range, less than $\pm 0.5 \mathrm{~m}$. It is notable that the Belfast North to South profile runs along the edge of the data, where the model solution is weakest (Fig. 12b). Four areas show a systematic shift (Belfast, Checkhall Trash, Checkhall, Pichelin). For the documentation
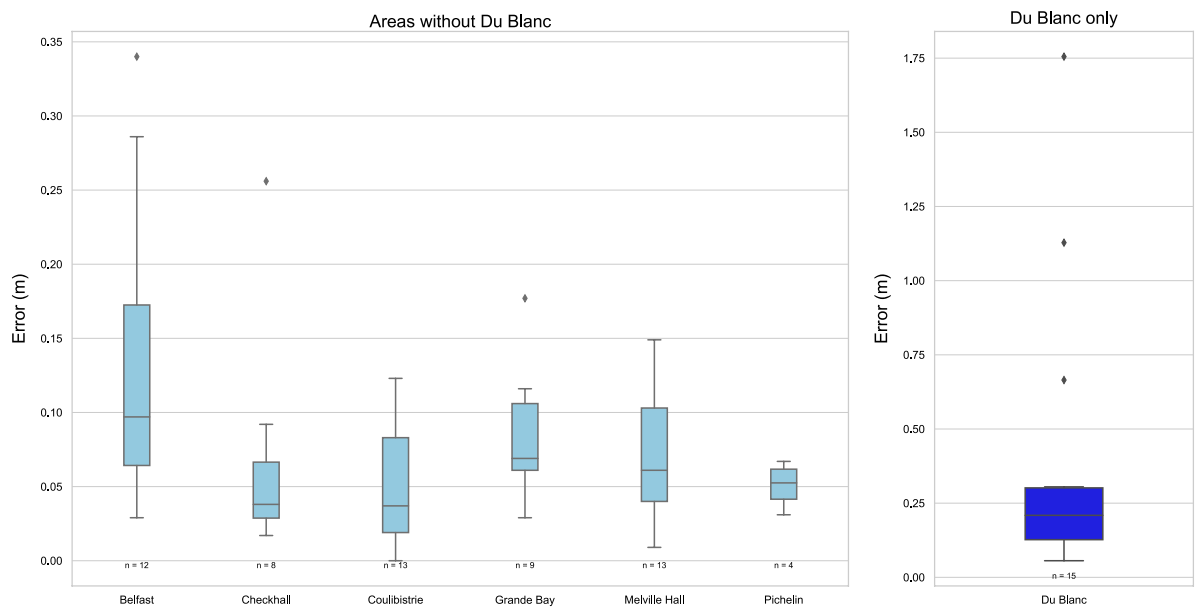

Fig. 11 Boxplot of the XY error of data processed using GCP (Jupyter/Matplotlib) 


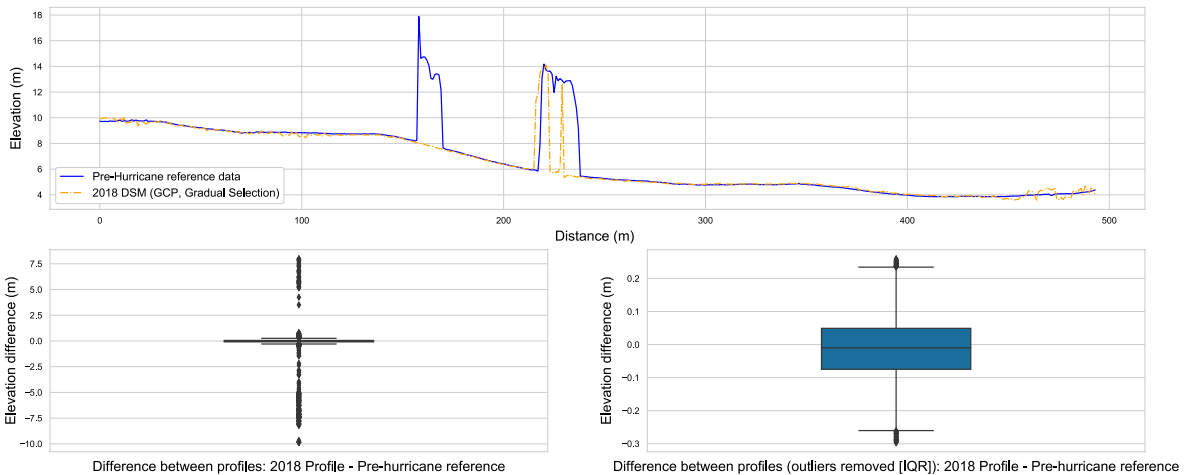

(a)

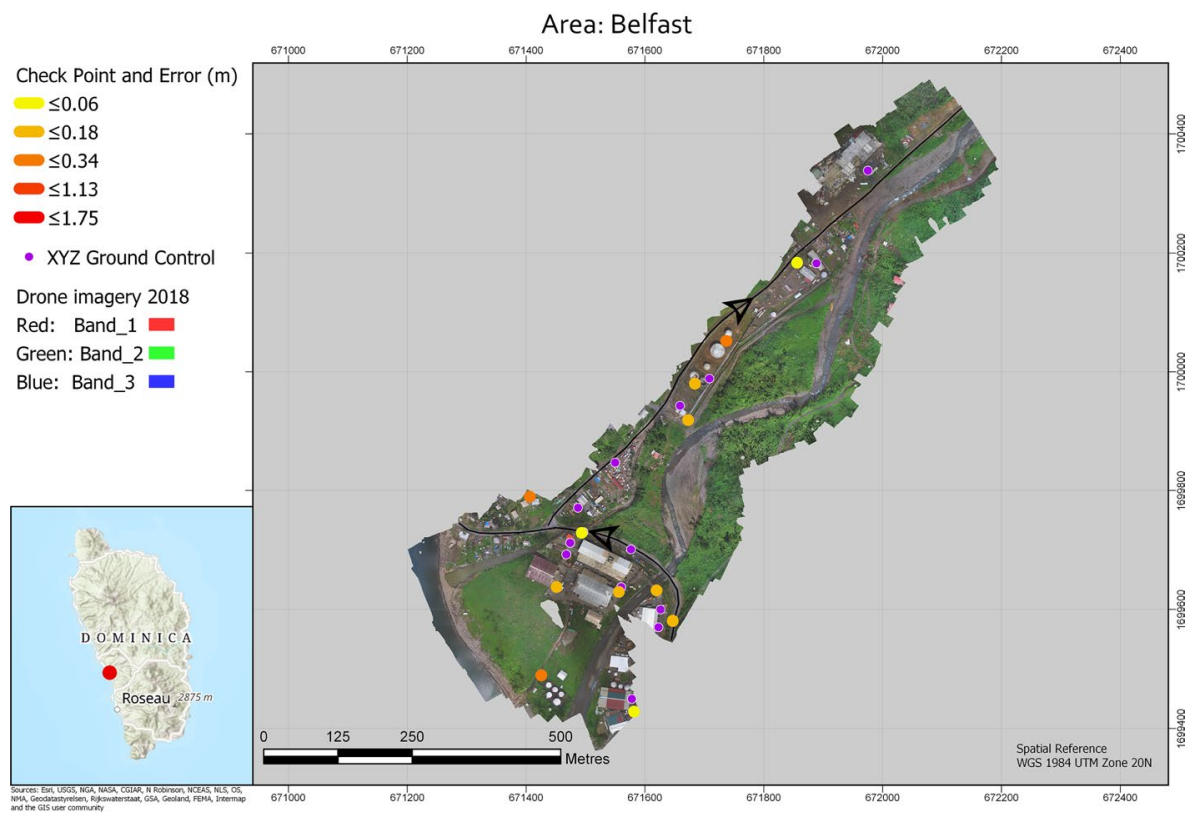

(b)

Fig. 12 Profile plot and map of data processed using GCP of Belfast, Dominica. a East to West profile plot comparing the 2017 reference data to the GCP derived 2018 data (Jupyter/Matplotlib). b Overview map showing the GCP, profiles and check points used in error assessment (Arcgis Pro 2.3)

of features and geomorphological assessment, however, morphology in local areas remains representative of real features (Fig. 14), as the doming effect applies to the whole model.

\section{Discussion}

The UAV survey described here was primarily designed to map the distribution of geoecological and geomorphological changes at locations where surface processes driven by hurricane Maria resulted in fatalities and/or major infrastructure damage. At eight of those 


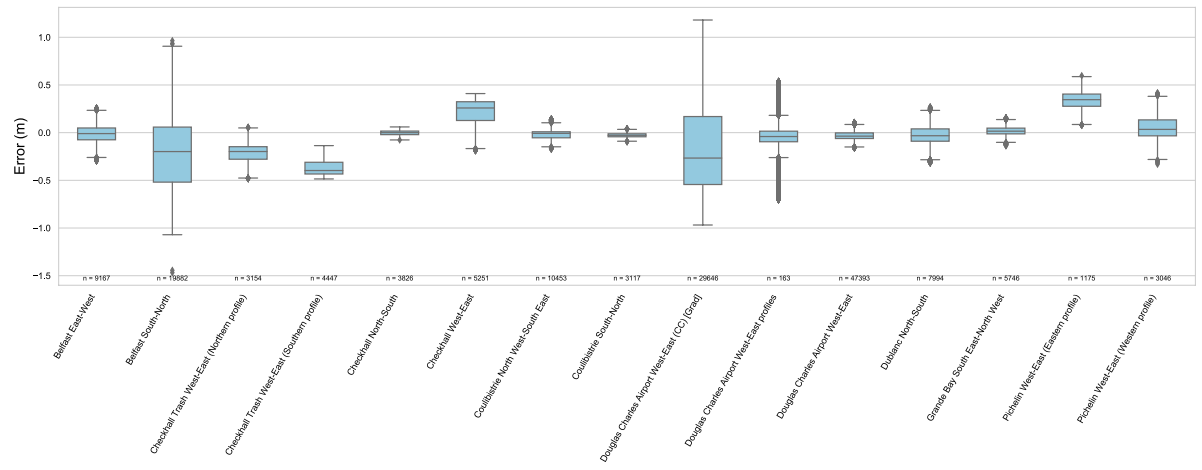

Fig. 13 Boxplot of the elevation profile error of data processed using GCP (Jupyter/Matplotlib)

locations, it was also possible to carry out change analysis, based on an earlier set of UAV surveys carried out a few weeks before hurricane Maria. This study has yielded many useful findings with regard to varying degrees of damage relative to the passage of hurricane Maria over Dominica: zones of storm surge run-up, coastal erosion and debris deposition; areas of river erosion, landslides and landslide-dams, locations of sediment deposition, boulder trains and tree debris. The survey also enabled a systematic analysis of the geomorphological settings of collapsed bridges, as well as the few bridges that survived the floods and debris flows, from which valuable 'build back better' features have been observed.

In the four months that elapsed between hurricane Maria and the bulk of the UAV damage surveys reported here (January/February 2018), the initial disaster response with search and rescue activity was followed by the humanitarian response with the provision of temporary shelter, food and medical supplies, emergency water and sanitation facilities. There was a major clean-up operation along all of the main roads and access roads in towns and villages, as well as at the ports and airports, lasting many months and culminating in the reconnection of electricity, water, sewerage and telecommunication links. Repairs to houses mostly involved initial temporary roofing with plastic tarpaulin and then re-roofing, typically with galvanised corrugated steel (tin roofs). At the time of the UAV surveys presented here, beyond the main roads and urban access roads, the debris from hurricane Maria—from the storm surge, floods, landslides and debris flows-largely remained undisturbed. One notable exception was some major engineering work along the main river through the capital, Roseau, during February 2018, with excavation of debris deposits from the main channel and the dumping of that debris a few miles away, mostly along the seaward margin of Canefield Airport.

This UAV survey was relatively rapid and cost-effective, with the 44 sites (listed in "Appendix") surveyed within 2 weeks by two survey drones, with two staff (the pilot and observer) per drone. Other survey methods were considered, but were relatively expensive, and/or less detailed with cloud-cover limitations, and/or could not be organised in the short time-frame of this project (see Table 2).

The discussion on survey cost is complex (DroneApps 2019), and services for aerial survey in particular are affected by the infrastructure of the surveyed district: getting a survey organised in the USA or UK is more straightforward than in less well-serviced lowincome countries. UAVs certainly also put surveys within the reach of smaller disaster 


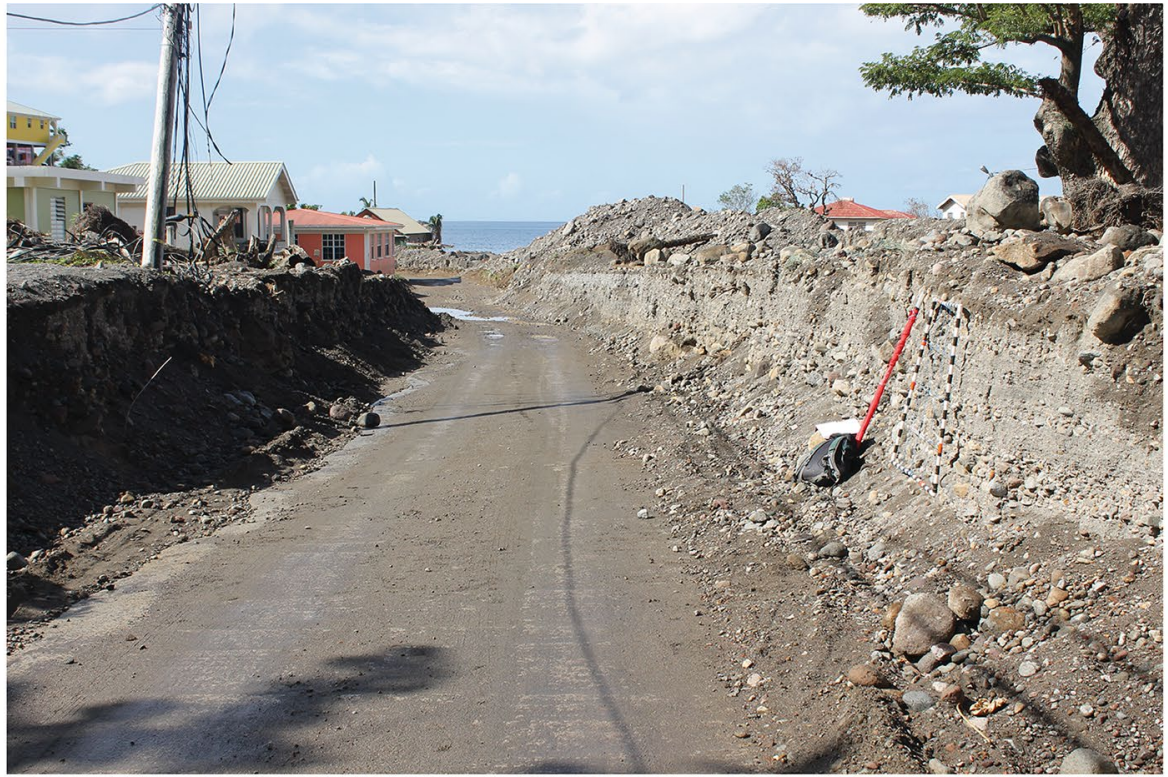

(a)

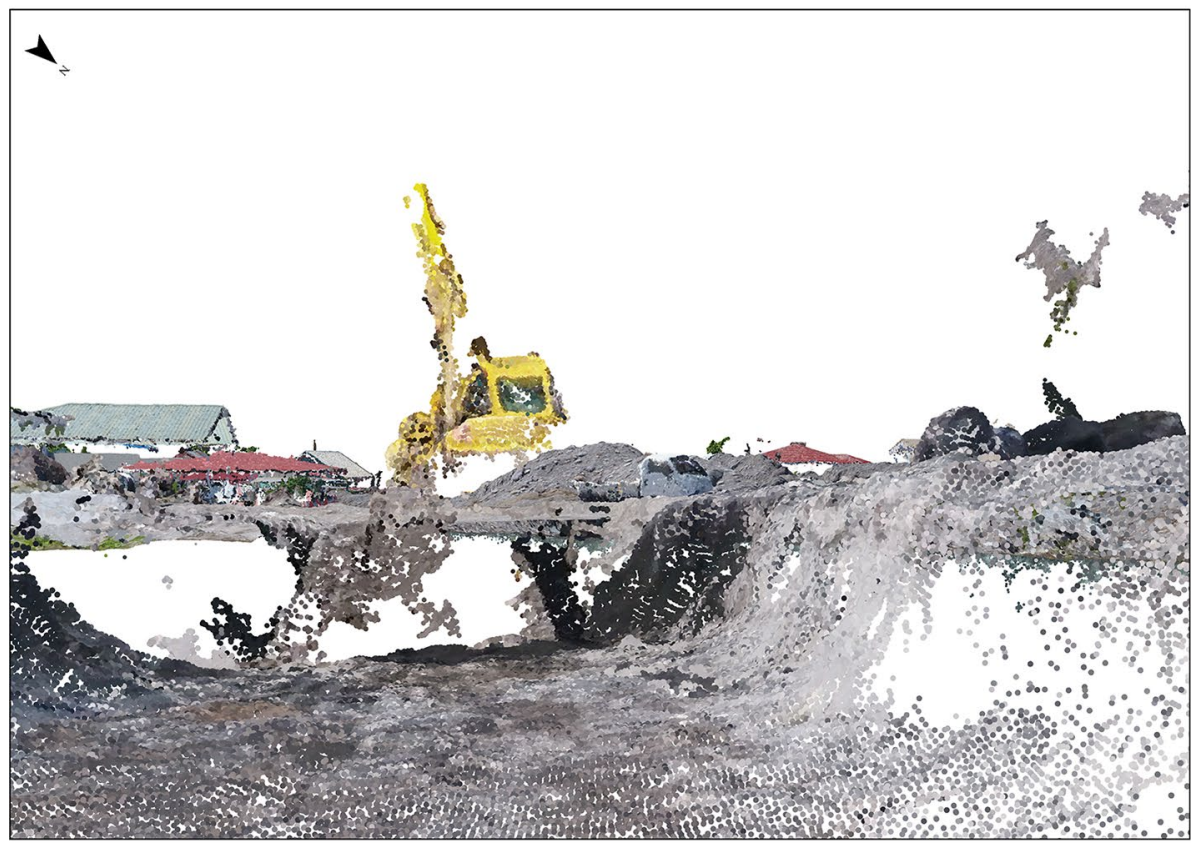

(b)

Fig. 14 Comparison of a picture taken in the field in Coulibistrie, Dominica, and the same vantage point simulated using the point cloud from the GCP processed data (Adobe Illustrator). a Field picture taken 07/02/2018. b Point cloud view 


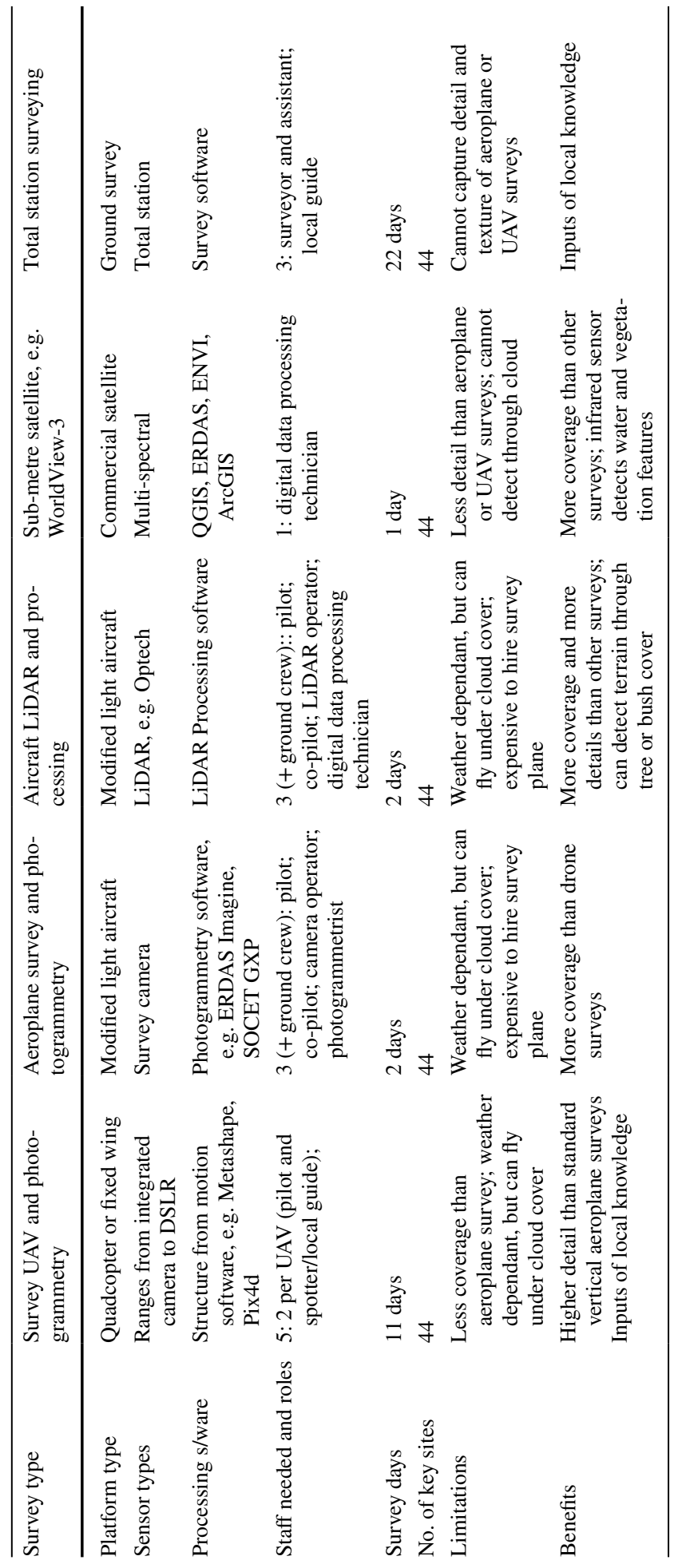


response NGOs. High-resolution optical satellite data, unless freely provided by satellite companies as part of a global relief effort, are made expensive by minimum order requirements and are often of limited use for image interpretation because of cloud cover, especially when carrying out damage assessments after storm disasters. Cloud cover can also be problematic for aerial laser scanning surveys, which is a particular issue with mountainous islands such as Dominica.

UAV capable of producing useful survey data can be purchased (at the time of writing) for less than US\$ 1000 (e.g. DJI Mavic, Yuneec Typhoon H), although UAV with a 1 inch sensor will provide better image quality for around US\$ 1800 (e.g. DJI Phantom 4 Pro v2.0, Yuneec H520). Recently, RTK solutions have been added to the line-up of commercial UAV companies (e.g. DJI Phantom 4 RTK, Yuneec H520 RTK), which cost ca. US\$ 10,000 . The training costs for becoming a commercial UAV pilot in the UK range from US\$ 600-1000. Although recommended, these qualifications may not be a requirement in the disaster management sector, and local regulations will vary. Building flying experience is required, however, and this may be achieved by joining a local model flying club and learning from hobbyists.

In order to assess the accuracy of UAV-derived data, a matching accurate data set is required. In cases where there is significant change between data, however, matching becomes highly challenging. DGNSS-derived GCP or RTK-processed direct referencing would provide the highest certainty of having accurate data for analysis (Barry and Coakley 2013; Javernick et al. 2014; Clapuyt et al. 2016; Turner et al. 2016), but is not always feasible due to logistical problems or high local costs in a post-disaster environment. The platform is therefore the main determining factor of the accuracy of the data for geomorphological mapping. When employing direct georeferencing without any GCP or RTK solutions, it is to be expected that a measure of inaccuracy is introduced due to (1) the GNSS data recorded, (2) the doming effect in SfM and (3) potential tilt in the elevation model. The second factor is therefore the data processing. Processing the data using default workflows is faster if batch processing large volumes of data, but provides less accurate data. It is therefore beneficial to have an automated process that can increase the accuracy of directly referenced data, and to some degree also GCP controlled data, by employing a gradual selection process in an automated process.

Employing GCP derived from secondary data significantly improves data accuracy, with due consideration of the reference data accuracy. The usefulness of the (Zekkos et al. 2018b) data to this study, both as a pre-event reference and to collect GCP, highlights the usefulness of baseline surveys in areas that are at risk from major hazard events. The best GCPs derived from this method are clear markers on a flat surface, removing all edge effects: road markings are good examples. The main issue around this is clearly the impact of hazard events that damage, or otherwise change, surface features. In 2017, there were clear DGNSS-derived GCP which have been obliterated in the (post-hurricane) 2018 data. If local mapping agencies, or agencies tasked with surveying, can target important infrastructure that is likely to survive extreme events, placing clear markers and performing a baseline survey, that would facilitate fast accurate response capabilities after hazard events. Even a programme of maintaining road markings to coincide with planned aerial surveys would increase the chance of good co-registration.

Despite these caveats, the accuracy of the UAV aerial photography and data processing in this project was sufficient to map out areas of sediment accretion and erosion in those areas that were not densely vegetated prior to Maria, with good agreement between the difference data obtained from the UAV work and on-the-ground measurement of deposited sediment thicknesses where this was possible. The data derived from this study will 
be processed further for future publications detailing the geomorphological changes and infrastructure implications. Our findings confirm that in areas where no previous data exist, non-RTK UAV-derived data can still provide important morphological data, taking into account a measure of doming and absolute positioning accuracy.

The results have demonstrated that low-cost UAV surveys can be a rapid, relatively accurate and cost-effective tool for disaster management applications, particularly damage assessments. UAVs are an accessible technology that requires a low investment in the equipment and training, potentially paying dividends in improved disaster preparedness, response and recovery. NGOs likely to work in countries at high risk from natural hazards, with many disaster management scenarios, could benefit from investing in the UAV survey technologies discussed in this article. Ideally previous map data should exist to rapidly assess changes, which can be captured for key sites by survey teams employed by government agencies or NGOs working with local authorities and volunteers. Furthermore, frequent repeat surveys and rapid production of appropriate processed data products during the disaster recovery and reconstruction phase would enable 'in-country' monitoring and management of relief work and reconstruction activities, reducing waste and duplication of effort. Such post-disaster surveys would provide 'in-country' community oversight and involvement in decision-making, as well as enabling monitoring of the longer-term environmental impacts of disaster events such as hurricane Maria. We emphasise that such a capacity would ideally need to be based upon 'in-country' data processing capabilities, using processing methodologies such as these described in this paper, as well as 'incountry' UAVs, although there would still be a need for continued involvement of various outside groups who could provide capacity for data backups to avoid the risk of loss of pre-disaster time series data sets in disasters, as well as additional capacities, training and processing upgrades.

In Dominica following hurricane Maria, there were two phases of UAV survey; within a day, amateur UAV operators were providing video imagery which could be used for rapid qualitative assessment of damage; more systematic surveys, such as those carried out by this team or Global Medics (https://globalmedic.ca/), had to wait until the main road infrastructure had been restored before accessing all sites where significant damage had occurred for systematic quantitative surveys.

We recommend engaging with the local government survey departments and relevant NGOs to provide training on baseline surveys. This can help in providing baseline surveys before a hazard event, and rapid response damage assessment surveys afterwards, based on volunteer video footage, photography or surveys. Although local volunteers may not have the skills or access to software to perform and process geospatial information, videos they capture in a structured manner can be compared to baseline data in a $3 \mathrm{D}$ environment for immediate assessment. It can often take at least $48 \mathrm{~h}$ before international relief teams arrive in an impacted country, with another $24 \mathrm{~h}$ needed for those teams to get secure accommodation and establish themselves in preparation for carrying out damage assessments and needs analysis. During that 2-3 day window local UAV survey teams could have collected valuable damage assessment data for the incoming international disaster assessment teams. Those datasets could be fed to the responding UN Disaster Assessment and Coordination (UNDAC) team, the local emergency management agency and NGOs such as MapAction (https://mapaction.org/), to provide immediate geospatial data for damage assessments and situation reports, saving many days in the disaster response process. In the disaster recovery and reconstruction phases, these local UAV survey teams can revisit impacted sites and re-capture the data to perform change analysis. A small team with a drone and a powerful laptop could conservatively process two 20 hectare site with two flights each and have 
the data in-hand by the next morning. With that data, immediate remedial work could be planned, with rebuilding modified to follow 'build back better' guidelines.

\section{Conclusion}

Accuracy assessment of UAV-derived data in a post-disaster survey context is not as straightforward as it is in a scientific evaluation carried out at an undisturbed location between surveys with good existing data and reference points. We have presented methods of processing and assessing UAV data from post-hurricane locations in Dominica and have shown that the data are as valid for geomorphological analysis and infrastructure damage assessment as GCP controlled or directly referenced data.

Although RTK-enabled UAV platforms would be the most accurate and safe system to use in these settings, this is not feasible in many cases, due to cost and logistics. GCPs derived from directly referenced UAV and secondary GCPs are highly applicable alternatives. Models derived from direct georeferencing without RTK correction require a more cautious approach: they provide a good overview of an area, but need to be treated as inaccurate if processed further, e.g. in flood models. Processing the data accurately and quickly is best done through a custom process and not through applying default batch parameters. The code is freely available, and copies can be modified to suit particular applications.

It is recommended that baseline imagery should be collected to enable rapid change detection. Guidelines are given on the locating and maintenance of the GCP that enable before-and-after change analysis to be carried out, providing geospatial data that can be used in studies of the hurricane-driven geomorphological processes that cause damage to infrastructure. Ideally, this would be an RTK solution, and alternatively, the team could work in conjunction with surveyors to use accurate GCP. If national mapping agencies created a network of permanent GCP around key sites—or at least simply ensured that road markings were frequently maintained-would aid in processing data more accurately. Pre-/ post-disaster change analysis would then become feasible if such a body of local GCP data existed. This would be especially useful if damage assessment surveys are organised in conjunction with local enthusiasts, who can provide UAV data but mostly will not use the relatively expensive RTK-enabled UAV. The script developed for this project allows nonspecialist users to quickly create models to map areas of loss or gain, which can then be used with GIS freeware, such as QGIS, to perform further geospatial analysis.

This project has provided a relatively low-cost and rapid methodology for accurately quantifying post-hurricane changes, assisting the disaster preparedness, recovery and reconstruction phases. We recommend that countries at high risk from natural disasters develop an 'in-country' UAV survey capacity, whether it be based on government agencies, NGOs or UAV enthusiast volunteers. As well as collecting pre-disaster baseline aerial photography and establishing ground control points, such UAV survey teams could respond within a few hours of a local disaster event, providing aerial photography that incoming disaster response teams urgently need for damage assessments.

Acknowledgements The surveys of January/February 2018 were funded by a UK NERC Urgency Grant awarded in December 2017, Ref: NE/RO16968/1. We are grateful for the support provided by the Dominica Ministry of Housing, Lands and Water Resources, the Ministry of Public Works and Ports, the Land Survey Department, the Department of Physical Planning and the Department of Local Government. We wish to thank the many Dominican people who assisted us in conducting this field survey, notably Don Corriette, Kennedy Ferguson, Wayne Abraham and Rob Watts. We further appreciate Mohammad Heidarzadeh allowing us to use some of his pictures from Dominica. 
Open Access This article is licensed under a Creative Commons Attribution 4.0 International License, which permits use, sharing, adaptation, distribution and reproduction in any medium or format, as long as you give appropriate credit to the original author(s) and the source, provide a link to the Creative Commons licence, and indicate if changes were made. The images or other third party material in this article are included in the article's Creative Commons licence, unless indicated otherwise in a credit line to the material. If material is not included in the article's Creative Commons licence and your intended use is not permitted by statutory regulation or exceeds the permitted use, you will need to obtain permission directly from the copyright holder. To view a copy of this licence, visit http://creativecommons.org/licenses/by/4.0/.

\section{Appendix}

List of areas surveyed in 2018 with the names used in processing and file naming and the area name as given in OpenStreetMap for reference. The table also shows the resolutions of the orthophotograph and the DSM, the centroid of the minimum bounding rectangle (MBR) of the orthophotograph and the area of the MBR as an indicator of coverage size. The MBR does not reflect the actual size of the area covered by the UAV data, it is a rectangle that completely contains it.

\begin{tabular}{|c|c|c|c|c|c|c|c|}
\hline Area & $\begin{array}{l}\text { Internal } \\
\text { area name }\end{array}$ & $\begin{array}{l}\text { Loca- } \\
\text { tion name } \\
\text { (OSM) }\end{array}$ & $\begin{array}{l}\text { Ortho } \\
\text { resolu- } \\
\text { tion }\end{array}$ & $\begin{array}{l}\text { DEM reso- } \\
\text { lution }\end{array}$ & $\begin{array}{l}\text { Centroid lon- } \\
\text { gitude }\end{array}$ & $\begin{array}{l}\text { Centroid } \\
\text { latitude }\end{array}$ & $\begin{array}{l}\text { MBR hec- } \\
\text { tares }\end{array}$ \\
\hline 1 & $\begin{array}{c}\text { Antrim } \\
\text { Estate }\end{array}$ & $\begin{array}{c}\text { Imperial } \\
\text { Road, } \\
\text { Antrim } \\
\text { Valley }\end{array}$ & 2.1 & 4.2 & -61.37214283 & 15.34375164 & 5.7 \\
\hline 2 & $\begin{array}{l}\text { Belfast } \\
\text { Estate }\end{array}$ & $\begin{array}{l}\text { Jimmit } \\
\text { Industrial } \\
\text { Road, } \\
\text { Belfast } \\
\text { River }\end{array}$ & 2.4 & 4.8 & -61.40029149 & 15.37041731 & 112.2 \\
\hline 3 & Bioche & Bioche & 3.2 & 6.3 & -61.4661057 & 15.5087246 & 10.9 \\
\hline 4 & Calibishie & Calibishie & 2.2 & 4.3 & -61.34900172 & 15.59327938 & 39.0 \\
\hline 5 & Campbell & $\begin{array}{l}\text { Campbell } \\
\text { and } \\
\text { Belfast } \\
\text { River }\end{array}$ & 2.7 & 5.3 & -61.37439131 & 15.37717753 & 65.1 \\
\hline 6 & $\begin{array}{l}\text { Castle } \\
\text { Bruce } \\
\text { North }\end{array}$ & $\begin{array}{l}\text { Belle Fille } \\
\text { River } \\
\text { mouth }\end{array}$ & 2.5 & 5.1 & -61.25829564 & 15.43143407 & 88.5 \\
\hline 7 & $\begin{array}{l}\text { Castle } \\
\text { Bruce } \\
\text { South }\end{array}$ & $\begin{array}{c}\text { Belle Fille } \\
\text { River, } \\
\text { Castle } \\
\text { Bruce } \\
\text { South }\end{array}$ & 2.4 & 4.7 & -61.27675745 & 15.41885936 & 11.0 \\
\hline 8 & $\begin{array}{l}\text { Castle Com- } \\
\text { fort }\end{array}$ & $\begin{array}{l}\text { River } \\
\text { Canari, } \\
\text { Castle } \\
\text { Comfort }\end{array}$ & 3.1 & 6.1 & -61.36986775 & 15.28638782 & 40.2 \\
\hline 9 & $\begin{array}{l}\text { Champagne } \\
\text { Pool }\end{array}$ & $\begin{array}{l}\text { Victoria } \\
\text { Street, } \\
\text { Cham- } \\
\text { pagne } \\
\text { Bay }\end{array}$ & 2.0 & 4.1 & -61.37266899 & 15.24743223 & 7.0 \\
\hline
\end{tabular}




\begin{tabular}{|c|c|c|c|c|c|c|c|}
\hline Area & $\begin{array}{l}\text { Internal } \\
\text { area name }\end{array}$ & $\begin{array}{l}\text { Loca- } \\
\text { tion name } \\
(\mathrm{OSM})\end{array}$ & $\begin{array}{l}\text { Ortho } \\
\text { resolu- } \\
\text { tion }\end{array}$ & $\begin{array}{l}\text { DEM reso- } \\
\text { lution }\end{array}$ & $\begin{array}{l}\text { Centroid lon- } \\
\text { gitude }\end{array}$ & $\begin{array}{l}\text { Centroid } \\
\text { latitude }\end{array}$ & $\begin{array}{l}\text { MBR hec- } \\
\text { tares }\end{array}$ \\
\hline 10 & $\begin{array}{l}\text { Checkhall } \\
\text { Trash }\end{array}$ & $\begin{array}{r}\text { Canefield } \\
\text { Airport }\end{array}$ & 2.0 & 3.9 & -61.39123164 & 15.33747294 & 62.8 \\
\hline 11 & Colihaut & Colihaut & 2.8 & 5.6 & -61.46259741 & 15.48488232 & 15.7 \\
\hline 12 & Coulibistrie & $\begin{array}{l}\text { Coulibistrie } \\
\text { River, } \\
\text { Coulibis- } \\
\text { trie }\end{array}$ & 2.1 & 4.3 & -61.45024709 & 15.46266154 & 40.8 \\
\hline 13 & Dasili & $\begin{array}{l}\text { Pt. Mulatre } \\
\text { River } \\
\text { mouth }\end{array}$ & 2.3 & 4.7 & -61.25575081 & 15.27581115 & 12.1 \\
\hline 14 & DosDan & $\begin{array}{l}\text { Blenheim } \\
\text { River, } \\
\text { Dos } \\
\text { D'Ane }\end{array}$ & 2.2 & 4.4 & -61.41162715 & 15.58441696 & 12.0 \\
\hline 15 & Dubiche & $\begin{array}{l}\text { Dubuc } \\
\text { River } \\
\text { mouth, } \\
\text { Dubuc }\end{array}$ & 1.7 & 3.5 & -61.30360839 & 15.24654547 & 6.1 \\
\hline 16 & Dublanc & Dublanc & 3.5 & 6.9 & -61.46705869 & 15.51396193 & 50.1 \\
\hline 17 & Grande Bay & $\begin{array}{l}\text { Geneva } \\
\text { River } \\
\text { mouth, } \\
\text { Grand } \\
\text { Bay Main } \\
\text { Road }\end{array}$ & 2.2 & 4.4 & -61.30794911 & 15.24522389 & 24.8 \\
\hline 18 & $\begin{array}{l}\text { LaPlane and } \\
\text { Rosali }\end{array}$ & $\begin{array}{l}\text { La Ronde } \\
\text { River } \\
\text { mouth, } \\
\text { Delices } \\
\text { Main } \\
\text { Road }\end{array}$ & 2.4 & 4.8 & -61.26323204 & 15.35523707 & 10.7 \\
\hline 19 & $\begin{array}{l}\text { Landslide } \\
\text { valley } \\
\text { LaPlane } \\
\text { and Rosali }\end{array}$ & $\begin{array}{l}\text { Mahaut } \\
\text { River, } \\
\text { North of } \\
\text { Morne } \\
\text { Jaune }\end{array}$ & 2.4 & 4.9 & -61.24550043 & 15.32110493 & 10.7 \\
\hline 20 & $\begin{array}{c}\text { Layou Val- } \\
\text { ley NE } 1\end{array}$ & $\begin{array}{l}\text { Layou } \\
\text { River, } \\
\text { Brookhill } \\
\text { Estate }\end{array}$ & 4.2 & 8.4 & -61.39749186 & 15.40870646 & 66.0 \\
\hline 21 & $\begin{array}{c}\text { Layou Val- } \\
\text { ley NE } 2\end{array}$ & $\begin{array}{l}\text { Layou } \\
\text { River, } \\
\text { South of } \\
\text { Brookhill } \\
\text { Estate }\end{array}$ & 3.7 & 7.3 & -61.40438297 & 15.40443953 & 28.9 \\
\hline 22 & $\begin{array}{r}\text { Layou Val- } \\
\text { ley SW } 1\end{array}$ & $\begin{array}{l}\text { Layou } \\
\text { River } \\
\text { mouth, } \\
\text { Layou }\end{array}$ & 3.4 & 7.3 & -61.42537715 & 15.39492596 & 26.9 \\
\hline
\end{tabular}




\begin{tabular}{|c|c|c|c|c|c|c|c|}
\hline Area & $\begin{array}{l}\text { Internal } \\
\text { area name }\end{array}$ & $\begin{array}{l}\text { Loca- } \\
\text { tion name } \\
(\mathrm{OSM})\end{array}$ & $\begin{array}{l}\text { Ortho } \\
\text { resolu- } \\
\text { tion }\end{array}$ & $\begin{array}{l}\text { DEM reso- } \\
\text { lution }\end{array}$ & $\begin{array}{l}\text { Centroid lon- } \\
\text { gitude }\end{array}$ & $\begin{array}{l}\text { Centroid } \\
\text { latitude }\end{array}$ & $\begin{array}{l}\text { MBR hec- } \\
\text { tares }\end{array}$ \\
\hline$\overline{23}$ & $\begin{array}{r}\text { Layou Val- } \\
\text { ley SW } 2\end{array}$ & $\begin{array}{l}\text { Layou } \\
\text { River, } \\
\text { Gad- } \\
\text { darkhan } \\
\text { Asphalt } \\
\text { Plant }\end{array}$ & 3.7 & 7.4 & -61.41648468 & 15.3988387 & 28.3 \\
\hline 24 & Loubiere E & $\begin{array}{l}\text { Grand Bay } \\
\text { Main } \\
\text { Road, } \\
\text { Loubiere } \\
\text { East }\end{array}$ & 2.1 & 4.2 & -61.3691707 & 15.27541803 & 12.8 \\
\hline 25 & $\begin{array}{l}\text { Loubiere } \\
\text { N } 1\end{array}$ & $\begin{array}{l}\text { River } \\
\text { Gillon } \\
\text { mouth, } \\
\text { Loubiere }\end{array}$ & 2.1 & 4.3 & -61.37177044 & 15.27833343 & 21.4 \\
\hline 26 & $\begin{array}{l}\text { Loubiere } \\
\text { N } 2\end{array}$ & $\begin{array}{l}\text { Unnamed } \\
\text { river } \\
\text { mouth, } \\
\text { Loubiere }\end{array}$ & 2.1 & 4.2 & -61.37333197 & 15.27611488 & 6.7 \\
\hline 27 & Loubiere S & $\begin{array}{l}\text { Loubiere } \\
\text { South }\end{array}$ & 4.5 & 9.0 & -61.37329896 & 15.27382795 & 18.3 \\
\hline 28 & $\begin{array}{l}\text { Marigot } \\
\text { Harbour }\end{array}$ & $\begin{array}{l}\text { Marigot } \\
\text { Port and } \\
\text { FIsheries } \\
\text { Complex }\end{array}$ & 2.1 & 4.3 & -61.28698777 & 15.54298997 & 10.8 \\
\hline 29 & $\begin{array}{l}\text { Melville } \\
\text { Hall }\end{array}$ & $\begin{array}{l}\text { Melville } \\
\text { Hall } \\
\text { River, } \\
\text { Douglas } \\
\text { Charles } \\
\text { Airport }\end{array}$ & 2.6 & 5.1 & -61.30013421 & 15.54691787 & 146.0 \\
\hline 30 & Picard River & $\begin{array}{l}\text { Picard } \\
\text { River, } \\
\text { Moo Cow } \\
\text { Trail }\end{array}$ & 2.1 & 4.1 & -61.4541178 & 15.55784563 & 17.5 \\
\hline 31 & Pichelin & $\begin{array}{l}\text { Pichelin, } \\
\text { Grand } \\
\text { Bay Main } \\
\text { Road }\end{array}$ & 2.0 & 4.0 & -61.32358052 & 15.2642638 & 11.2 \\
\hline 32 & $\begin{array}{l}\text { Point } \\
\text { Michelle }\end{array}$ & $\begin{array}{l}\text { Ravine } \\
\text { Sibouli, } \\
\text { Pointe } \\
\text { Michel }\end{array}$ & 2.1 & 4.1 & -61.37430343 & 15.25852836 & 20.9 \\
\hline 33 & Portsmouth & $\begin{array}{l}\text { Bay Street, } \\
\text { Ports- } \\
\text { mouth } \\
\text { North }\end{array}$ & 2.1 & 4.2 & -61.4629824 & 15.58352323 & 12.9 \\
\hline 34 & $\begin{array}{l}\text { Portsmouth } \\
\text { Power } \\
\text { Station }\end{array}$ & $\begin{array}{l}\text { Barry } \\
\text { River, } \\
\text { East of } \\
\text { Ports- } \\
\text { mouth }\end{array}$ & 1.9 & 3.7 & -61.44027442 & 15.57620468 & 3.9 \\
\hline
\end{tabular}




\begin{tabular}{|c|c|c|c|c|c|c|c|}
\hline Area & $\begin{array}{l}\text { Internal } \\
\text { area name }\end{array}$ & $\begin{array}{l}\text { Loca- } \\
\text { tion name } \\
\text { (OSM) }\end{array}$ & $\begin{array}{l}\text { Ortho } \\
\text { resolu- } \\
\text { tion }\end{array}$ & $\begin{array}{l}\text { DEM reso- } \\
\text { lution }\end{array}$ & $\begin{array}{l}\text { Centroid lon- } \\
\text { gitude }\end{array}$ & $\begin{array}{l}\text { Centroid } \\
\text { latitude }\end{array}$ & $\begin{array}{l}\text { MBR hec- } \\
\text { tares }\end{array}$ \\
\hline 35 & $\begin{array}{l}\text { Road Near } \\
\text { Pennville }\end{array}$ & $\begin{array}{l}\text { Northern } \\
\text { Link } \\
\text { Road, } \\
\text { Delaford } \\
\text { Estate }\end{array}$ & 1.1 & 2.3 & -61.4280942 & 15.62668532 & 0.9 \\
\hline 36 & Rosali & $\begin{array}{l}\text { Rosalie } \\
\text { River, } \\
\text { Rosalie } \\
\text { Bay } \\
\text { Resort }\end{array}$ & 2.1 & 4.3 & -61.25370894 & 15.37260255 & 23.0 \\
\hline 37 & $\begin{array}{l}\text { Roseau } \\
\text { River NE }\end{array}$ & $\begin{array}{l}\text { Roseau } \\
\text { River and } \\
\text { River } \\
\text { Blanc } \\
\text { conflu- } \\
\text { ence }\end{array}$ & 4.1 & 8.1 & -61.34024638 & 15.32159633 & 63.9 \\
\hline 38 & $\begin{array}{l}\text { Roseau } \\
\text { River SW }\end{array}$ & $\begin{array}{l}\text { Roseau } \\
\text { River, } \\
\text { Fond Cani } \\
\text { to Bath } \\
\text { Estate }\end{array}$ & 2.3 & 4.6 & -61.36658889 & 15.30871262 & 901.6 \\
\hline 39 & $\begin{array}{r}\text { Scott's } \\
\text { Head }\end{array}$ & $\begin{array}{l}\text { Victoria } \\
\text { Street } \\
\text { coastal } \\
\text { strip, } \\
\text { Scott's } \\
\text { Head }\end{array}$ & 1.9 & 3.7 & -61.36583239 & 15.21862033 & 164.9 \\
\hline 40 & $\begin{array}{l}\text { Scott's } \\
\text { Head } \\
\text { Road } \\
\text { Landslide }\end{array}$ & $\begin{array}{l}\text { Victoria } \\
\text { Street, } \\
\text { East of } \\
\text { Pointe } \\
\text { Guignard } \\
\text { Estate }\end{array}$ & 1.9 & 3.8 & -61.36379403 & 15.24281177 & 4.3 \\
\hline 41 & Soufriere & $\begin{array}{l}\text { Soufriere } \\
\text { Estate }\end{array}$ & 3.3 & 6.6 & -61.3534418 & 15.23569605 & 64.1 \\
\hline 42 & Toucari & Toucari & 1.7 & 3.5 & -61.46445983 & 15.61027047 & 5.7 \\
\hline 43 & Trafalgar & $\begin{array}{l}\text { Roseau } \\
\text { River, } \\
\text { Papillote } \\
\text { Wilder- } \\
\text { ness } \\
\text { Retreat }\end{array}$ & 3.9 & 7.8 & -61.3379273 & 15.32642147 & 32.0 \\
\hline 44 & $\begin{array}{l}\text { Unspeci- } \\
\text { fied } 1\end{array}$ & $\begin{array}{l}\text { Stock Farm } \\
\text { Street, } \\
\text { Roseau }\end{array}$ & 2.2 & 4.5 & -61.37878515 & 15.31040662 & 1.5 \\
\hline
\end{tabular}

\section{References}

AgiSoft (2017) About. https://www.agisoft.com/about/. Accessed 23 Jan 2017

Agisoft (2018) Agisoft PhotoScan user manual professional edition, version 1.4. 
Agisoft Forum (2018) Altitude used in processing UAV (DJI Phantom 4 Pro). https://www.agisoft.com/ forum/index.php?topic $=8306.0$. Accessed 20 Dec 2018

Barry P, Coakley R (2013) Field accuracy test of RPAS photogrammetry. Int Arch Photogramm Remote Sens Spat Inf Sci 2:27-31. https://doi.org/10.5194/isprsarchives-XL-1-W2-27-2013

Caroti G, Martínez-Espejo Zaragoza I, Piemonte A (2015) Accuracy assessment in structure from motion 3d reconstruction from uav-born images: the influence of the data processing methods. Int Arch Photogramm Remote Sens Spat Inf Sci 4:103-109. https://doi.org/10.5194/isprsarchi ves-XL-1-W4-103-2015

Clapuyt F, Vanacker V, Van Oost K (2016) Reproducibility of UAV-based earth topography reconstructions based on structure-from-motion algorithms. Geomorphology 260:4-15. https://doi. org/10.1016/j.geomorph.2015.05.011

CloudCompare (2015) Alignment and registration-CloudCompareWiki. In: CloudCompareWiki. https ://www.cloudcompare.org/doc/wiki/index.php?title=Alignment_and_Registration. Accessed 7 Nov 2018

De Reu J, Plets G, Verhoeven G et al (2013) Towards a three-dimensional cost-effective registration of the archaeological heritage. J Archaeol Sci 40:1108-1121. https://doi.org/10.1016/j.jas.2012.08.040

DroneApps (2019)Price wars: counting the cost of drones, planes and satellites. DroneApps DroneApps. https://droneapps.co/price-wars-the-cost-of-drones-planes-and-satellites/. Accessed 24 Oct 2019

Government of Dominica (2017) Post-disaster needs assessment hurricane Maria. p 161

Greenwood WW, Lynch JP, Zekkos D (2019) Applications of UAVs in civil infrastructure. J Infrastruct Syst 25:04019002. https://doi.org/10.1061/(ASCE)IS.1943-555X.0000464

Harwin S, Lucieer A, Osborn J (2015) The impact of the calibration method on the accuracy of point clouds derived using unmanned aerial vehicle multi-view stereopsis. Remote Sens (Basel) 7:11933-11953. https://doi.org/10.3390/rs70911933

Humanitarian UAV Network Docs-humanitarian UAV network. https://uaviators.org/docs. Accessed 18 Dec 2018

James MR, Robson S (2014) Mitigating systematic error in topographic models derived from UAV and ground-based image networks. Earth Surf Process Landf 39:1413-1420. https://doi.org/10.1002/ esp.3609

James MR, Robson S, d'Oleire-Oltmanns S, Niethammer U (2017a) Optimising UAV topographic surveys processed with structure-from-motion: ground control quality, quantity and bundle adjustment. Geomorphology 280:51-66. https://doi.org/10.1016/j.geomorph.2016.11.021

James MR, Robson S, Smith MW (2017b) 3-D uncertainty-based topographic change detection with structure-from-motion photogrammetry: precision maps for ground control and directly georeferenced surveys. Earth Surf Process Landf 42:1769-1788. https://doi.org/10.1002/esp.4125

Javernick L, Brasington J, Caruso B (2014) Modeling the topography of shallow braided rivers using structure-from-motion photogrammetry. Geomorphology 213:166-182. https://doi.org/10.1016/j. geomorph.2014.01.006

Mallison H (2015) Photogrammetry tutorial 11: how to handle a project in Agisoft Photoscan I dinosaurpalaeo. https://dinosaurpalaeo.wordpress.com/2015/10/11/photogrammetry-tutorial-11-how-tohandle-a-project-in-agisoft-photoscan/. Accessed 3 July 2018

Marcel (2015) Alignment experiments. In: Alignment experiments. https://www.agisoft.com/forum/ index.php?topic $=3559.0$. Accessed 6 Nov 2018

Marius R, Hill S, Hooman L (2017) Best practice tutorial: technical handling of the UAV "DJI Phantom 3 Professional" and processing of the acquired data

Mertes JR, Gulley JD, Benn DI et al (2017) Using structure-from-motion to create glacier DEMs and orthoimagery from historical terrestrial and oblique aerial imagery. Earth Surf Process Landf 42:2350-2364. https://doi.org/10.1002/esp.4188

OCHA (2014) Unmanned aerial vehicles in humanitarian response. OCHA policy and studies series

Pasch RJ, Penny AB, Berg R (2018) Hurricane Maria (AL 152017). National hurricane center tropical cyclone report

Schaefer M (2018) Photoscan automation script 6.2. Github

Schaefer M, Woodyer T (2015) Assessing absolute and relative accuracy of recreation-grade and mobile phone GNSS devices: a method for informing device choice. Area 47:185-196. https://doi. org/10.1111/area.12172

Turner D, Lucieer A, Watson C (2012) An automated technique for generating georectified mosaics from ultra-high resolution unmanned aerial vehicle (UAV) imagery, based on structure from motion (SfM) point clouds. Remote Sens (Basel) 4:1392-1410. https://doi.org/10.3390/rs4051392

Turner D, Lucieer A, Wallace L (2014) Direct georeferencing of ultrahigh-resolution UAV imagery. IEEE Trans Geosci Remote Sens 52:2738-2745. https://doi.org/10.1109/TGRS.2013.2265295 
Turner IL, Harley MD, Drummond CD (2016) UAVs for coastal surveying. Coast Eng 114:19-24. https ://doi.org/10.1016/j.coastaleng.2016.03.011

Université catholique de Louvain EM-DAT: the emergency events database. https://www.emdat.be/datab ase. Accessed 8 Feb 2019

USGS PhotoScan processing procedures DSLR Mar 2017

Westoby MJ, Brasington J, Glasser NF et al (2012) 'Structure-from-Motion' photogrammetry: a low-cost, effective tool for geoscience applications. Geomorphology 179:300-314. https://doi. org/10.1016/j.geomorph.2012.08.021

Zekkos D, Greenwood W, Lynch J et al (2018a) Lessons learned from the application of UAV-enabled structure-from-motion photogrammetry in geotechnical engineering. ISSMGE Int J Geoeng Case Hist 4(4):254-274. https://doi.org/10.4417/IJGCH-04-04-03

Zekkos D, Manousakis J, Clark M (2018b) Digital surface model creation of select floodplains in Dominica. University of Michigan Geotechnical Engineering Research Report, Ann Arbor (Submited to World Bank)

Publisher's Note Springer Nature remains neutral with regard to jurisdictional claims in published maps and institutional affiliations.

\section{Affiliations}

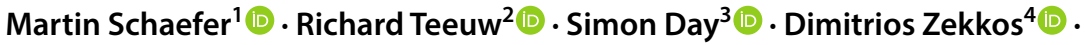 Paul Weber ${ }^{1}(1) \cdot$ Toby Meredith $^{5} \cdot$ Cees J. van Westen ${ }^{6}$ (])}

Richard Teeuw

richard.teeuw@port.ac.uk

Simon Day

simon.day@ucl.ac.uk

Dimitrios Zekkos

zekkos@geoengineer.org

Paul Weber

paul.weber@port.ac.uk

Toby Meredith

toby.meredith@port.ac.uk

Cees J. van Westen

c.j.vanwesten@utwente.nl

1 School of the Environment, Geography and Geosciences, University of Portsmouth, Buckingham Building, Lion Terrace, Portsmouth PO1 3HE, UK

2 School of the Environment, Geography and Geosciences, University of Portsmouth, Burnaby Building, Burnaby Road, Portsmouth PO1 3QL, UK

3 Faculty of Maths and Physical Sciences, Institute for Risk and Disaster Reduction, University College London, London, UK

4 Department of Civil and Environmental Engineering, University of California at Berkeley, Davis Hall, Berkeley, CA 94556, USA

5 Faculty of Creative and Cultural Industries, University of Portsmouth, Eldon Building, Winston Churchill Avenue, Portsmouth PO1 2DJ, UK

6 Department of Earth Systems Analysis, University of Twente, Enschede, The Netherlands 